\title{
Bone fragility in patients affected by congenital diseases non skeletal in origin
}

\author{
L. Masi ${ }^{1}$, S. Ferrari' ${ }^{2}$, M. K. Javaid ${ }^{3}$, S. Papapoulos ${ }^{4}$, D. D. Pierroz ${ }^{5}$, M. L. Brandi ${ }^{6,7^{*}}$ (D) and IOF Skeletal Rare Diseases \\ Working Group
}

\begin{abstract}
Background: Bone tissue represents a large systemic compartment of the human body, with an active metabolism, that controls mineral deposition and removal, and where several factors may play a role. For these reasons, several non-skeletal diseases may influence bone metabolism. It is of a crucial importance to classify these disorders in order to facilitate diagnosis and clinical management. This article reports a taxonomic classification of non-skeletal rare congenital disorders, which have an impact on bone metabolism
\end{abstract}

Methods: The International Osteoporosis Foundation (IOF) Skeletal Rare Diseases Working Group (SRD-WG), comprised of basic and clinical scientists, has decided to review the taxonomy of non-skeletal rare disorders that may alter bone physiology.

Results: The taxonomy of non-skeletal rare congenital disorders which impact bone comprises a total of 6 groups of disorders that may influence the activity of bone cells or the characteristics of bone matrix.

Conclusions: This paper provides the first comprehensive taxonomy of non-skeletal rare congenital disorders with impact on bone physiology.

Keywords: Bone metabolism, Genetic bone diseases, Metabolic bone diseases, Taxonomy, Non-skeletal rare congenital disorders

\section{Background}

In the past decade, spectacular progress has been made in the understanding of the molecular basis of congenital diseases and syndromes (https://www.eurordis.org/; www.orpha.net/). These mechanistic insights, in combination with the development of effective treatments, in a few cases engineered to target specific causes, have resulted in a significant increase in survival of the affected patients. A consequence of this longer life expectancy for patients, who previously died in infancy or at a very young age, is the development of signs and symptoms related to the genetic disorder and the related phenotype.

*Correspondence: marialuisa.brandi@unifi.it

${ }^{6}$ Fondazione Italiana Ricerca sulle Malattie dell'Osso, Florence, Italy

Full list of author information is available at the end of the article
Bone tissue represents a large systemic compartment of the human body, with an active metabolism, that controls mineral deposition and removal. The dynamic process of bone turnover is the basis for a large number of local and systemic factors which control the function of bone cells [1]. This pleiotropic system is mirrored by an increasing prevalence of secondary osteoporosis, caused by a myriad of factors [2]. The recent classification of congenital metabolic bone disorders enabled identification of 116 Online Mendelian Inheritance in $\mathrm{Man}^{\circledR}\left(\mathrm{OMIM}^{\circledR}\right)$ phenotypes with 86 affected genes, whose defects are based on recognized cellular and biochemical regulators of bone turnover [3].

In the present review, we report non-skeletal rare congenital diseases, which impact bone mass, bone quality and/or bone metabolism. The scope of this effort is to develop a taxonomic work in order to establish a platform original author(s) and the source, provide a link to the Creative Commons licence, and indicate if changes were made. The images or other third party material in this article are included in the article's Creative Commons licence, unless indicated otherwise in a credit line to the material. If material is not included in the article's Creative Commons licence and your intended use is not permitted by statutory regulation or exceeds the permitted use, you will need to obtain permission directly from the copyright holder. To view a copy of this licence, visit http://creativecommons.org/licenses/by/4.0/. The Creative Commons Public Domain Dedication waiver (http://creativeco mmons.org/publicdomain/zero/1.0/) applies to the data made available in this article, unless otherwise stated in a credit line to the data. 
for the recognition of characteristics and treatments of bone metabolic complications when these are the consequence of a non-skeletal rare congenital disease.

We are aware that to realize a complete classification is impossible. However, by this work we developed a first classification of systemic rare diseases not skeletal in nature, that influence bone metabolism. These facts open to the use of the drugs indicated for osteoporosis in areas not previously considered as pharmacological targets.

The present job will be revisited over time by the group of experts in order to update the paper and insert new disorders and potential drugs useful to treat the bone metabolic alterations.

\section{Methods}

The present review was performed according to the following steps:

Step 1 involved a discussion by the scientists representing the IOF Skeletal Rare Diseases Working Group (SRD-WG) on the need to identify the non-skeletal rare congenital disorders which impact bone.

In step 2 the working group decided to identify relevant studies through a research strategy characterized by an evaluation on PUBMED. Systematic literature search on www.pubmed.gov using the term: Metabolic Rare Diseases, Liver Rare Diseases, Respiratory Rare Disease, Hematological Rare Diseases, Neurological Rare Diseases and Malformations. Inside to these big areas we selected the "congenital disorders".

In step 3, for each congenital disorders we added the term "osteoporosis" or "bone mass", or "bone turnover" or "bone fragility" or "skeletal fractures", or "bone biomarkers" or "biochemical", "therapy" and we choose the most relevant studies.

Six groups of congenital disorders, which impact bone metabolism, were recognized. For each group a brief report regarding the pathogenesis of the disorders, the impact on bone metabolism was developed. The groups of diseases are described in Tables 1, 2, 3, 4, and 5.

Acronyms for the disorders were described with phenotype and gene/locus numbers presented according to the nomenclature of Online Mendelian Inheritance in Men ${ }^{\circledR}\left(\mathrm{OMIM}^{\circledR}\right)$ database, as accessed on July 2014 (https ://www.ncbi.nlm.nih.gov/omim). An OMIM entry preceded by a number sign (\#) indicates the phenotype and specific OMIM entries for the genes/loci whose mutations have been shown as responsible for that phenotype (https://web.udl.es/dept/cmb/biomatica/OMIM.PDF). The names of genes/loci are those approved by HGNC (HUGO Gene Nomenclature Committee, https://www. genenames.org).
The scope of the present paper is to classify non-skeletal rare congenital disorders with an impact on bone physiology on the basis of phenotypes. Information of bone metabolism in these disorder is also included. The manuscript was conceived and written by the members of the IOF SRD-WG.

The diseases have been homogenously described following this scheme:

- Description of the systemic disease

- Genetic defect

- Pathophysiology of bone phenotype

- Therapy

A brief description of the bone phenotype and altered biomarkers, when available, has been reported for each disease and for cases for which this information missing the term "NR" (not reported) is included.

The therapy for the systemic disease has been described if available and studies on drugs used to treat the bone damage were present in the literature.

The alteration of bone metabolism requires a particular attention considering that, due to better targeted therapies, patients survive into adulthood and in many cases the loss of bone mass may be an important problem with an impact on the quality of life.

An adequate patient education in term of intake of calcium, vitamin D and physical activity should be recommended. Currently, the best advice is to treat osteopenia and/or osteoporosis according to general guidelines using anti-resorbitives or anabolic drugs.

In Fig. 1, the available non disease-specific diagnostic assays, which could be of use to further refine the diagnosis, have been listed, as previously described [3].

\section{Metabolic rare diseases \\ Lysosomal storage diseases \\ Description of the systemic disease}

The identification of the lysosome as a cellular organelle responsible for intracellular digestion and recycling of macromolecules [4-7] led to the understanding of the physiological basis of the Lysosomal Storage Diseases (LSDs), as a heterogeneous group of over 50 rare inherited disorders characterized by the accumulation of undigested or partially digested macromolecules, which ultimately results in cellular dysfunction and clinical abnormalities [8]. The constellation of dysmorphic features also includes bony abnormalities (dysostosis multiplex) [8]. Symptoms are typically gradually progressive rather than episodic, as occurs with other neurometabolic disorders.

Classically, LSDs encompass enzyme deficiencies of the lysosomal hydrolases. A classical LSD is Type 


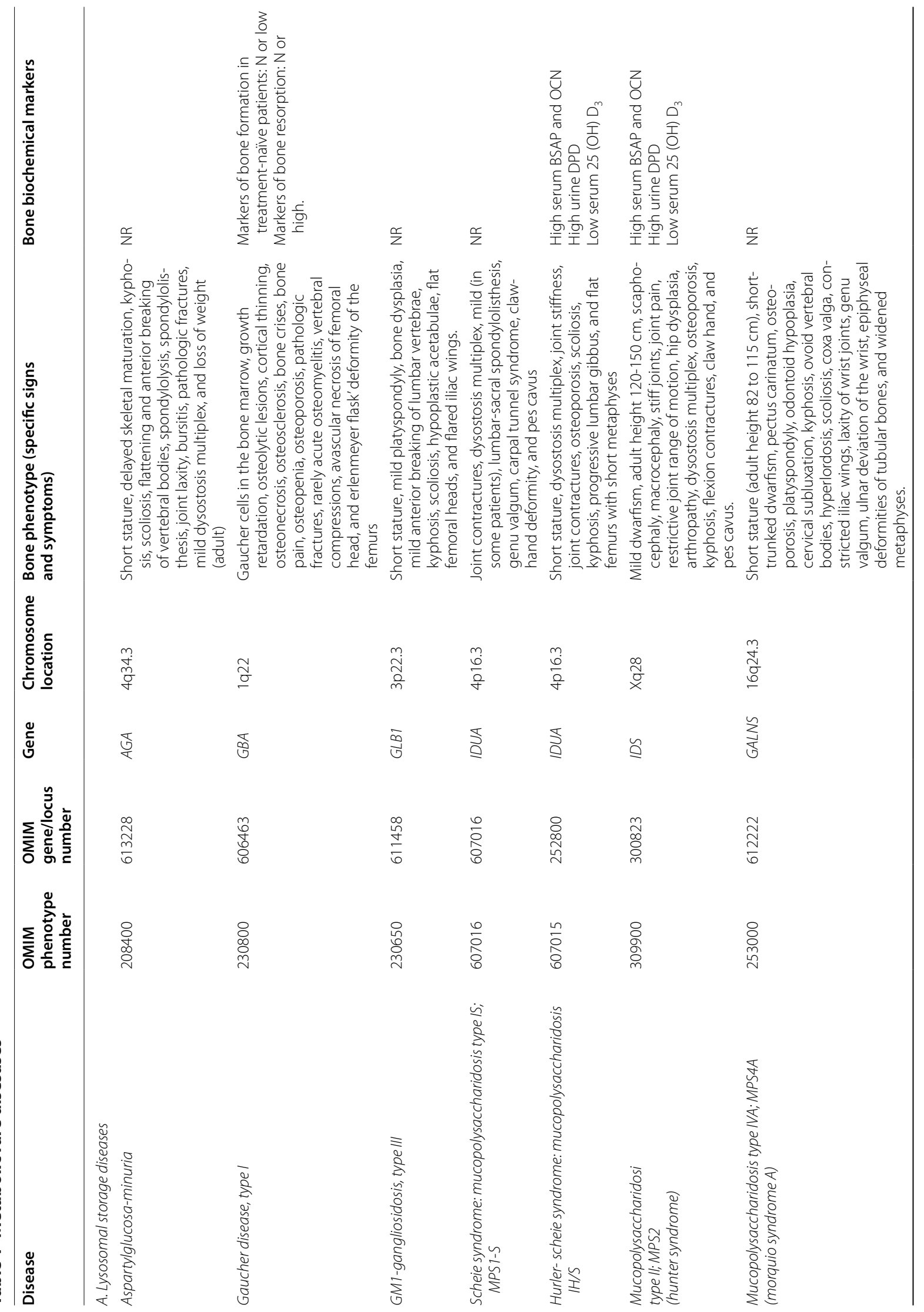




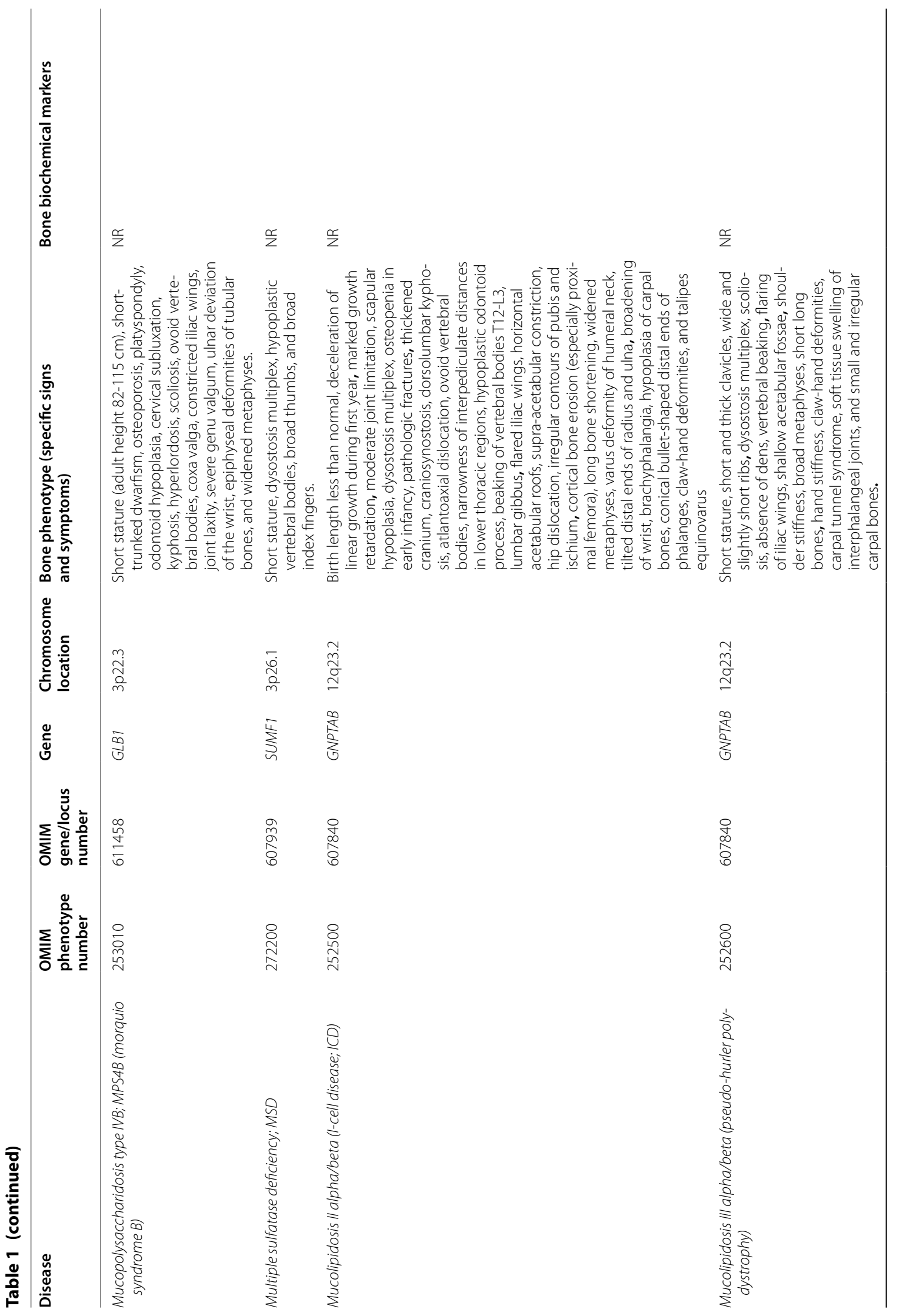




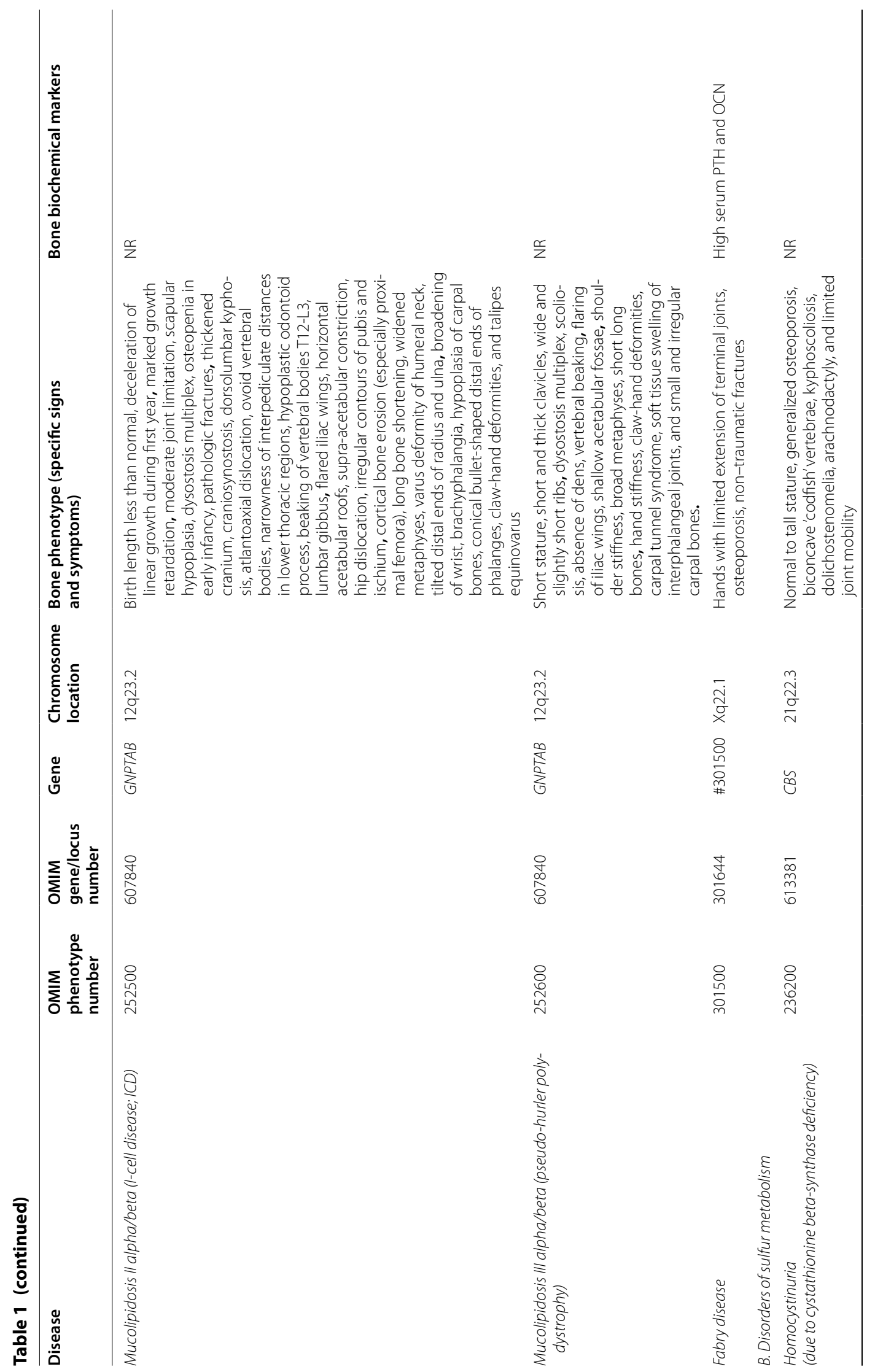




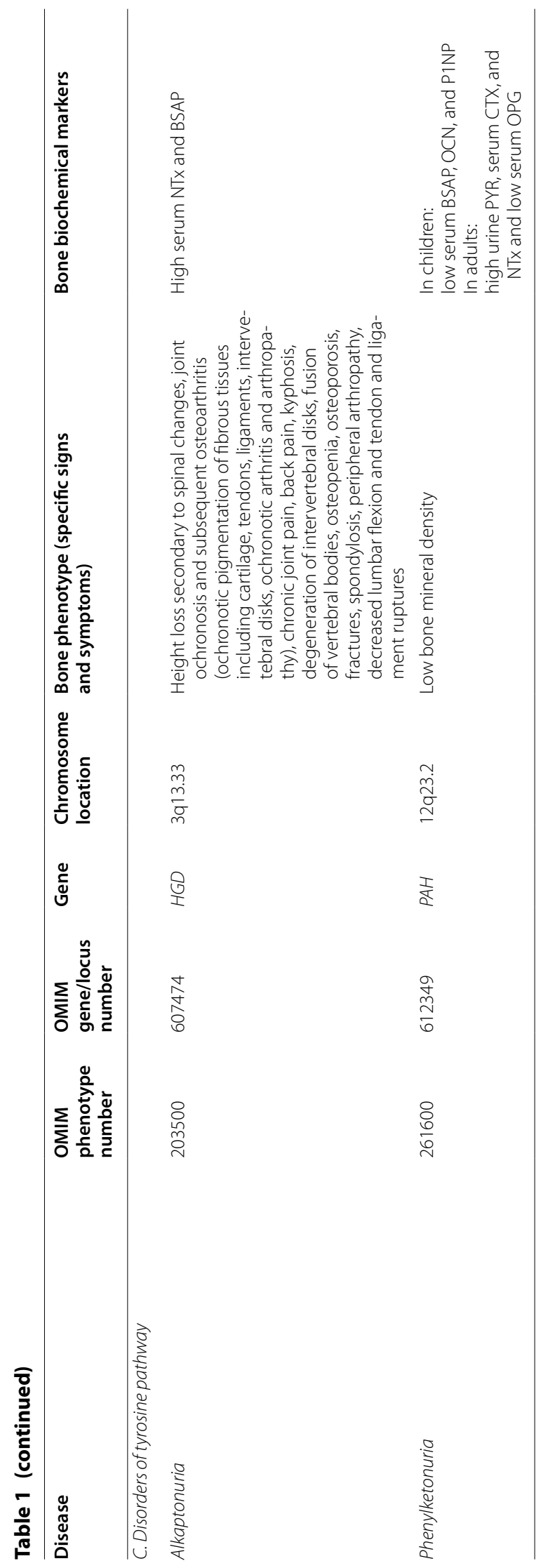


Table 2 Liver rare diseases

\begin{tabular}{|c|c|c|c|c|c|c|}
\hline Disease & $\begin{array}{l}\text { OMIM } \\
\text { phenotype } \\
\text { number }\end{array}$ & $\begin{array}{l}\text { OMIM } \\
\text { gene/locus } \\
\text { number }\end{array}$ & Gene & $\begin{array}{l}\text { Chromosome } \\
\text { location }\end{array}$ & Bone phenotype (specific signs and symptoms) & $\begin{array}{l}\text { Bone } \\
\text { biochemical markers }\end{array}$ \\
\hline \multicolumn{7}{|c|}{ Disorders of copper pathway } \\
\hline Menkes disease & 309400 & 300011 & ATP7A & Xq21.1 & $\begin{array}{l}\text { Intrauterine growth retardation, failure to thrive, } \\
\text { short stature, Wormian bones, osteoporosis, joint } \\
\text { laxity, and metaphyseal widening with spurs } \\
\text { A milder form is occasionally seen in males with mild } \\
\text { intellectual disability, muscle weakness, tremor, } \\
\text { ataxia, connective tissue signs, pili torti, and later- } \\
\text { onset seizures }\end{array}$ & NR \\
\hline Wilson disease & 277900 & 606882 & ATP7B & $13 q 14.3$ & $\begin{array}{l}\text { Osteoporosis, osteomalacia, pathological fractures, } \\
\text { chondrocalcinosis, osteoarthritis, and joint hyper- } \\
\text { mobility }\end{array}$ & $\begin{array}{l}\text { High urine phosphate } \\
\text { and calcium } \\
\text { Low serum calcium } \\
\text { Low PTH }\end{array}$ \\
\hline
\end{tabular}

Table 3 Respiratory rare disease

\begin{tabular}{|c|c|c|c|c|c|c|}
\hline Disease & $\begin{array}{l}\text { OMIM phenotype } \\
\text { number }\end{array}$ & $\begin{array}{l}\text { OMIM gene/locus } \\
\text { number }\end{array}$ & Gene & $\begin{array}{l}\text { Chromosome } \\
\text { location }\end{array}$ & $\begin{array}{l}\text { Bone phenotype } \\
\text { (specific signs } \\
\text { and symptoms) }\end{array}$ & $\begin{array}{l}\text { Bone } \\
\text { Biochemical Markers }\end{array}$ \\
\hline Cystic fibrosis & 219700 & 602421 & CFTR & $7 q 31.2$ & $\begin{array}{l}\text { Failure to thrive, defective } \\
\text { height-weight growth, } \\
\text { osteoporosis, non-trau- } \\
\text { matic fractures }\end{array}$ & $\begin{array}{l}\text { High serum CTX } \\
\text { Low serum } 25(\mathrm{OH}) \mathrm{D}_{3}\end{array}$ \\
\hline
\end{tabular}

1 Gaucher disease (GD) a $\beta$-glucocerebrosidase deficiency, which is a relatively common LSD, particularly within the Ashkenazi Jewish community. In 1882, it was the first of these disorders to be described [9], followed by Fabry disease in 1898 [10].

More recently, the concept of lysosomal storage disease has been expanded to include deficiencies or defects in proteins necessary for the normal posttranslational modification of lysosomal enzymes (which themselves are often glycoproteins), activator proteins, or proteins important for proper intracellular trafficking between the lysosome and other intracellular compartments [11]. Age of onset and clinical manifestations may vary widely among patients with a given lysosomal storage disease, and significant phenotypic heterogeneity between family members carrying identical mutations has been reported [12]. LSDs are generally classified by the accumulated substrate and include the sphingolipidoses, oligosaccharidoses, mucolipidoses, mucopolysaccharidoses (MPSs), lipoprotein storage disorders, lysosomal transport defects, neuronal ceroid lipofuscinoses, and others.

\section{Genetic defects}

In each case, lysosomal storage diseases are caused by an inborn error of metabolism that results in the absence or deficiency of an enzyme, leading to the inappropriate storage of material in various cells of the body. While most lysosomal storage disorders are inherited in an autosomal recessive pattern, there are exceptions. Fabry disease and Hunter syndrome follow an X-linked recessive inheritance pattern. The genes associated with many lysosomal storage disorders have been identified. The genes involved in the pathogenesis of the disorders and the chromosome location are indicated in Table 1A.

\section{Pathophysiology of bone phenotype}

Lysosomes have been isolated from cartilage, bone and synovial tissues. In pathological conditions, increased numbers of lysosomes have been observed by super resolution microscopy and electron microscopy in animal and human tissues [13], in particular rheumatoid synovium [13] and experimentally produced arthritis [14].

The in vitro studies showed that the initial degradation of extracellular matrix is due, at least in part, to the extracellular function of lysosomal enzymes released from viable cartilage and bone cells [13]. Further, it was shown 
Table 4 Hematological rare diseases

\begin{tabular}{|c|c|c|c|c|c|c|}
\hline Disease & $\begin{array}{l}\text { OMIM } \\
\text { phenotype } \\
\text { number }\end{array}$ & $\begin{array}{l}\text { OMIM } \\
\text { gene/locus } \\
\text { number }\end{array}$ & Gene & $\begin{array}{l}\text { Chromosome } \\
\text { location }\end{array}$ & $\begin{array}{l}\text { Bone phenotype (specific } \\
\text { signs and symptoms) }\end{array}$ & Bone biochemical markers \\
\hline Mastocytosis & 154800 & 164920 & KIT & $4 q 12$ & $\begin{array}{l}\text { Osteopenia, osteoporosis } \\
\text { with/without fractures } \\
\text { osteolytic or osteosclerotic } \\
\text { bone lesions due to mast } \\
\text { cell infiltration, primarily } \\
\text { affecting the axial skeleton } \\
\text { and ends of the long bone }\end{array}$ & $\begin{array}{l}\text { High serum BSAP and urine } \\
\text { DPD }\end{array}$ \\
\hline Beta-thalassemia major & 613985 & 141900 & $H B B$ & $11 p 15.4$ & $\begin{array}{l}\text { Osteopenia and osteoporosis } \\
\text { with/or without fractures }\end{array}$ & $\begin{array}{l}\text { Low PTH and } 25(\mathrm{OH}) \mathrm{D}_{3} \\
\text { High serum IL-1a, } \\
\text { TNF-a and IL-6 } \\
\text { Low serum OCN }\end{array}$ \\
\hline $\begin{array}{l}\text { Hemophilia } \\
\text { Type A }\end{array}$ & 306700 & 300841 & $F$ & $X q 28$ & Osteoporosis & High serum P1NP \\
\hline $\begin{array}{l}\text { Hemophilia } \\
\text { Type } B\end{array}$ & 306900 & 300746 & F9 & Xq27.1 & Osteoporosis & High serum P1NP \\
\hline sickle cell disease & 603903 & 141900 & $H B B$ & $11 p 15.4$ & $\begin{array}{l}\text { Avascular joint necrosis; Joint } \\
\text { and leg pain; osteopenia/ } \\
\text { osteoporosis }\end{array}$ & $\begin{array}{l}\text { Low serum calcium and high } \\
\text { serum phosphate, } \\
\text { High serum BSAP }\end{array}$ \\
\hline $\begin{array}{l}\text { Ghosal hemato-diaphyseal } \\
\text { dysplasia }\end{array}$ & 231095 & 274180 & TBXAS1 & $7 q 34$ & $\begin{array}{l}\text { Increased bone density; } \\
\text { diaphyseal dysplasia; thick } \\
\text { long bones of the extremi- } \\
\text { ties; wide diaphyseal } \\
\text { medullary cavities; cortical } \\
\text { hyperostosis } \\
\text { Variable phenotype; most } \\
\text { patients present in infancy } \\
\text { with anemia }\end{array}$ & $N R$ \\
\hline $\begin{array}{l}\text { Severe congenital neutrope- } \\
\text { nia } 1\end{array}$ & 202700 & 130130 & ELANE & $19 p 13.3$ & Osteopenia/osteoporosis & NR \\
\hline $\begin{array}{l}\text { Severe congenital neutrope- } \\
\text { nia } 2\end{array}$ & 613107 & 600871 & GFI1 & $1 \mathrm{q} 22.1$ & Osteopenia/osteoporosis & $N R$ \\
\hline $\begin{array}{l}\text { Severe congenital neutrope- } \\
\text { nia } 3\end{array}$ & 610738 & 605998 & HAX1 & $1 \mathrm{q} 21.3$ & Osteopenia/osteoporosis & NR \\
\hline $\begin{array}{l}\text { Severe congenital neutrope- } \\
\text { nia } 4\end{array}$ & 612541 & 611045 & G6PC3 & $17 q 21.31$ & $\begin{array}{l}\text { Osteopenia/osteoporosis; } \\
\text { poor growth; pectus } \\
\text { carinatum; proximal locali- } \\
\text { zation of thumb; broad } \\
\text { thumbs }\end{array}$ & $N R$ \\
\hline $\begin{array}{l}\text { Severe congenital neutrope- } \\
\text { nia } 5\end{array}$ & 615285 & 610035 & VPS45A & $1 \mathrm{q} 21.2$ & Osteopenia / osteoporosis & NR \\
\hline $\begin{array}{l}\text { Severe congenital neutrope- } \\
\text { nia } 6\end{array}$ & 616022 & 616012 & JAGN1 & $3 p 25.3$ & $\begin{array}{l}\text { Short stature; osteopenia / } \\
\text { osteoporosis }\end{array}$ & $N R$ \\
\hline $\begin{array}{l}\text { Severe congenital neutrope- } \\
\text { nia } 7\end{array}$ & 617014 & 138971 & CSF3R & 1 p34.3 & Osteopenia/osteoporosis & $N R$ \\
\hline $\begin{array}{l}\text { Severe congenital neutropenia } \\
\quad x \text {-linked }\end{array}$ & 300299 & 300392 & WAS & Xp11.23 & Osteopenia/osteoporosis & $N R$ \\
\hline \multicolumn{7}{|l|}{ Histiocytosis } \\
\hline $\begin{array}{l}\text { Langerhans cell histiocytosis } \\
\text { (X-Histiocytosis }\end{array}$ & & & & & $\begin{array}{l}\text { Lytic bone lesions at skull, } \\
\text { but any bone may be } \\
\text { involved, painless or pain- } \\
\text { ful, and possible associated } \\
\text { soft-tissue mass. }\end{array}$ & $N R$ \\
\hline $\begin{array}{l}\text { Non-Langerhans cell histio- } \\
\text { cytosis (Erdheum-Chester } \\
\text { Disease) }\end{array}$ & & & & & $\begin{array}{l}\text { Osteosclerosis of the long } \\
\text { bones, bone pain, (mainly } \\
\text { affecting the distal lower } \\
\text { limbs). }\end{array}$ & $N R$ \\
\hline
\end{tabular}


Table 5 Neurological rare diseases

\begin{tabular}{|c|c|c|c|c|c|c|}
\hline Disease & $\begin{array}{l}\text { OMIM } \\
\text { phenotype } \\
\text { number }\end{array}$ & $\begin{array}{l}\text { OMIM gene/ } \\
\text { locus number }\end{array}$ & Gene & $\begin{array}{l}\text { Chromosome } \\
\text { location }\end{array}$ & $\begin{array}{l}\text { Bone phenotype } \\
\text { (specific signs and symptoms) }\end{array}$ & $\begin{array}{l}\text { Bone } \\
\text { biochemical markers }\end{array}$ \\
\hline Rett Syndrome & 312750 & 300005 & MECP2 & Xq28 & $\begin{array}{l}\text { Short stature, deceleration of } \\
\text { head growth, scoliosis, and } \\
\text { growth retardation, kyphosis, } \\
\text { small feet, peripheral vasomotor } \\
\text { disturbance, muscle wasting, } \\
\text { usually low bone mineral den- } \\
\text { sity, high risk of fractures } \\
\text { The evolution and severity of the } \\
\text { disease are heterogeneous and } \\
\text { several atypical variants were } \\
\text { observed }\end{array}$ & $\begin{array}{l}\text { Low bone turnover in the modeling } \\
\text { period of childhood and youth, } \\
\text { normal bone turnover in adults } \\
\text { with the exception of higher } \\
\text { serum BSAP }\end{array}$ \\
\hline
\end{tabular}

that this initial degradation allowed diffusion of products out of the matrix and stimulated their endocytosis by chondrocytes, osteocytes and fibroblasts, and the digestion is completed within the digestive vacuoles of these cells. Extracellular digestion that takes place during the bone erosion process is due to the activity of osteoclastic cells, characterized by the presence of a large number of lysosomes [13], where enzymes, when released on bone surfaces, are able to degrade the extracellular matrix. It is, therefore, not surprising that the majority of LSDs have bone involvement. It occurs frequently in GD patients, in which it is one of most debilitating complication, reducing the quality of life of patients $[15,16]$. However, in GD patients, the pathogenic basis of bone complications is not fully understood [16]. The need for a routine analysis of bone turnover, bone mass and bone quality features is
Biochemical markers

- Serum Calcium

- Urinary Calcium

- Serum Phosphate

- Urinary Phosphate

- Serum Magnesium

- Parathyroid Hormone (PTH)

- Fibroblast growth factor 23 (FGF23)

- 25 hydroxyvitmaina D3 $\left[25(\mathrm{OH}) \mathrm{D}_{3}\right]$

- 1,25 dihydroxyvitamin D3 $\left[1-25(\mathrm{OH})_{2} \mathrm{D}_{3}\right.$

- Bone Formation Markers:

Total Alkaline Phosphatase, Bone Alkaline Phosphatase, Osteocalcin, Procollagen $1 \mathrm{~N}$-terminal Propetife (P1NP), Procollagen $1 \mathrm{C}$-terminal Propetide (P1CP)

- Bone Resorption Markers: Hydroxyproline, Piridinoline and Deoxypiridinoline, Cross-linked N-telopeptide of type I collagen (NTX), Cross-linked C-telopeptide of type collagen (CTX)

- Bone Mineralization Markers: Puridoxal-5'-phosphate; Urinary 4-pyridoxic acid

- Bone Microenvironment Products Sclerostin, RANK-Ligand, Osteoprotegerin

\section{Instrumental exams}

- DEXA: Lumabr Spine, hip, wrist, total body

- Ultrasound (US): heel, finger

- Peripheral Quantitative Computed Tomography (pQCT): leg, wrist

- Quantitative Computed Tomography (QCT): spine

- X-rays

- Radiographic vertebral morphometry

- DEXA: Vertebral Fracture Assessment (VFA)

- Bono scintigraphy

- Positron Emission Tomography (PET)

- Magnetic Resonance Imagin (MRI)

\section{Bone biopsy \\ - Histology \\ - Histomorphometry}

In vitro assays

Fig. 1 Biochemical/instrumental exams and in vitro tests for characterizing metabolic bone involvement [3] 
strongly recommended in these patients, as this will facilitate pharmacological intervention preferentially with antiresorptives and/or targeted metabolic drugs.

\section{Therapy}

The enzyme replacement therapy (ERT) often fails to adequately correct the manifestations of the disease in the CNS and other organs such as bone, cartilage, cornea, and heart. Targeted enzyme delivery systems (EDSs) can efficiently cross biological barriers such as the blood-brain barrier (BBB) and provide maximal therapeutic results with minimal side effects, and hence, offer great clinical benefits over the currently used conventional ERT. The classical ERT has been beneficial in MPS patients, improving their survival rate. However, some difficulties have impaired the therapeutic values of ERT, including the inability of enzymes in crossing the $\mathrm{BBB}$, their low stability, and the requirement for an early treatment to prevent the occurrence of irreversible clinical manifestations. Thus, it is essential to use less aggressive and more effective treatment modalities in newborn patients to avoid more-aggressive interventions later in life. Multifunctional nanomedicines have been introduced as the novel strategies to circumvent these limitations and increase the effectiveness of the ERT. Nano-scaled liposomes and polymers conjugated with specific cell surface receptors provide a new approach in targeting the desired cells. This strategy is still in its infancy period, however it could provide a costeffective approach with high rate of success [17].

In Table 1A, LSD disorders are described, along with accompaining systemic and bone signs and symptoms.

\section{Disorders of sulfur metabolism Homocystinuria}

Description of the systemic disease. Several defects can exist in the conversion of the sulfur-containing amino acid methionine to cysteine and the ultimate oxidation of cysteine to inorganic sulfate [18]. The most relevant disorder is rapresented by homocystinuria. Cystathionine$\beta$-synthase (CBS) is a crucial regulator of plasma concentrations of homocysteine (HCY) [18]. It catalyzes the pyridoxal 5'-phosphate (PLP)-dependent'-replacement reaction in which the thiolate of L-homocysteine replaces the hydroxyl group of L-serine [19]. CBS is an especially interesting PLP enzyme because it has a complex domain structure and regulatory mechanism. The allosteric activator, S-adenosyl-L-methionine (AdoMet), increases CBS activity about threefold, and likely binds to the C-terminal regulatory domain [19].

The clinical features of untreated homocystinuria due to CBS deficiency usually manifest in the first or second decade of life and include myopia, ectopia lentis, mental retardation, skeletal anomalies resembling Marfan syndrome (MFS), and thromboembolic events. Light skin and hair can also be present. It is extremely heterogeneous, ranging from patients presenting with all of the complications to individuals with no overt clinical involvement. Biochemical features include increased urinary homocystine and methionine. There are 2 main phenotypes of the classic disorder: a milder pyridoxine (vitamin B6)-responsive form, and a more severe pyridoxine-nonresponsive form. Pyridoxine is a cofactor for the CBS enzyme, and can aid in the conversion of homocysteine to cysteine [20-22].

Genetic defects Classic homocystinuria is an autosomal recessive metabolic disorder of sulfur metabolism. The human hereditary disease is characterized by very high plasma levels of the toxic amino acid L-homocysteine. The gene coding CBS is localized on chromosome 21q22.3. A large number of mutations in different regions of the human CBS have been found in patients with homocystinuria [19, $23,24]$. Mutations in the CBS gene can alter the mRNA stability, the enzyme activity, the binding of PLP and heme and the allosteric regulation. Rarely, homocystinuria can be caused by mutations in other genes. The enzymes encoded by the MTHFR, MTR, MTRR, and MMADHC genes play a role in converting homocysteine to methionine [23-25].

Pathophysiology of bone phenotype Severe hyperhomocysteinemia due to CBS deficiency confers diverse clinical manifestations, including typical skeletal abnormalities. This aspect of hyperhomocysteinemia has been investigated in the skeleton of cbs-deficient mice, a murine model of severe hyperhomocysteinemia, characterized by impaired cartilage differentiation, albeit to differing degrees $[25,26]$. Interestingly, basal levels of $c b s$ gene mRNA and protein in MC3T3-E1 murine pre-osteoblasts appear to increase after incubation with 1,25-dihydroxyvitamin $\mathrm{D}_{3}\left[1,25(\mathrm{OH})_{2} \mathrm{D}_{3}\right]$ providing evidence of a transcriptional regulation of the vitamin $\mathrm{D}$ receptor (VDR) [26], with a possible supporting role for calcitriol on the action of folic acid, vitamin B6, and B12 in lowering high HCY levels [27].

Some of the skeletal abnormalities, are due to the fact that cysteine deficiency, which occurs in hyperhomocysteinemia due to CBS deficiency, can induce a fibrillin-1 defect [28].

Because collagen cross-links are important for the stability and strength of the bone matrix, CBS deficiency patients are prone to fragile bone [29]. In addition, homocysteine levels increase the risk of fractures, independent of bone mineral density (BMD) and other potential 
risk factors for fracture [29, 30], likely for a disruption of a normal microfibrillar configuration [22].

Therapy For early diagnosed patients, treatment can realistically aim to prevent all the complications of CBS deficiency, as normal growth and nutrition, allowing the patient normal opportunities for employment and family life. For late-diagnosed patients, the aim is to prevent further complications, especially thromboembolic disease. Good compliance with low dietary methionine restriction treatment prevented ectopia lentis, osteoporosis and thromboembolic events and it also led to normal cognitive functions. Enzyme replacement therapy based on polyethylene glycol (PEG)ylated 20NHS CBS conjugate represents the most suitable candidate for manufacturing and clinical development [31].

Table 1B describes only homocystinuria phenotype disease as the main disorder of sulfur metabolism, where bone involvement has been described.

\section{Disorders of tyrosine metabolism Description of the systemic disease}

Tyrosine is one of the 20 standard amino acids that are used by cells to synthesize proteins. Phenylalanine hydroxylase (PAH) converts phenylalanine to tyrosine. Tyrosine can also be found in dairy products, meats, fish, eggs, nuts, beans, oats, and wheat. Tyrosine is a precursor of several neurotransmitters (e.g. dopamine, norepinephrine, epinephrine), hormones (e.g. thyroxine), and melanin. Deficiency of enzymes involved in its metabolism leads to a variety of syndromes. Alkaptonuria and phenylketonuria are the two main diseases due to a tyrosine pathway alteration with an impact on bone metabolism.

\section{Alkaptonuria}

Genetic defects Alkaptonuria is an inherited disorder of aromatic amino acid metabolism and results from absence of homogentisate 1,2 dioxygenase (HGD), the enzyme predominantly produced by hepatocytes in the liver and in the kidney, responsible for the breakdown of homogentisic acid (HGA). Deficient HGD activity within the liver causes HGA levels to rise systemically. Large (gram) quantities of HGA are removed by urinary excretion on a daily basis [32,33].

It is an autosomal recessive genetic disease, meaning that patients have inherited two defective copies of a gene; one from each parent. By 1995, the genetic defect was discovered, cloned, and mapped to chromosome 3 between regions 3q21-q23 [32-34].

Pathophysiology of the bone phenotype The development of transgenic mice and in vitro models have enabled a better understanding of the pathophysiology involved in the progression of ochronosis and the related osteoarthropathy. Research has identified that HGA is present in healthy cartilage but becomes susceptible to degeneration only following focal changes [35]. Indeed, extracellular matrix (ECM) is normally resistant to ochronosis, but may become susceptible to pigmentation in response to tissue biochemical or mechanical damage, including microtrauma [35]. Pigmentation appears to protect collagen fibers from the action of proteolytic enzymes, contributing to increased tissue stiffness. This is a probable cause of higher susceptibility to matrix damage through normal loading [35]. Pigmentation is shown to begin in the pericellular and territorial matrices of individual chondrocytes and, thus, matrix turnover events in these regions could be an important factor for initiation of pigmentation into the hyaline cartilage $[35,36]$. This process of enhanced osteoclastic activity resorbing the unloading subchondral bone and calcified cartilage is similar to the manifestation reported in osteoarthritis [37-40]. Although aggressive resorption appears to be focal, it is noteworthy that enhanced urinary excretion of crosslinked N-telopeptides of type I collagen has been reported in alkaptonuria patients [34]. In addition, Aliberti et al. [41] showed an increase of bone resorption along with an almost normal bone formation in patients with alkaptonuria, suggesting an enlarged bone remodeling space. In term of bone mass, they found conflicting results about spinal and femoral BMD, as lumbar spine BMD was normal or markedly increased, whilst femoral neck BMD was almost always reduced [41]. It is likely that BMD of lumbar spine might not be reliably assessed in these particular patients. It may be hypothesized that the homogentisic acid polymer deposit in the bone matrix and osteocytes may play a pathophysiological role in accelerating bone loss [41]. It is plausible that in a bone tissue diffusely osteoporotic, the ochronotic pigment is deposited in bone matrix and osteocytes with degenerated or dead cells [41].

Therapy In a phase 3 study patients with AKU were given $2 \mathrm{mg}$ of nitisinone each day for three years. Newly published results show that the drug stops the disease, by decreasing HGA. Further, nitisinone therapy not only arrested but also partially reversed ochronosis. Results also show that it significantly reduces the damage caused by ochronosis, especially in the joints. Patients who took nitisinone showed major health benefits [42].

\section{Phenylketonuria}

Genetic defects Phenylketonuria (PKU) is a genetic disorder caused by mutations in the gene coding for PAH. As a consequence, the essential amino acid phenylalanine 
(Phe) cannot be converted to tyrosine and accumulates in the blood.

The human PAH gene, which is located on chromosome 12q, consists of 13 exons spanning $90 \mathrm{~kb}$. To date, more than 520 different mutations in the $P A H$ gene have been characterized in PKU patients and recorded in the PAH Mutation Analysis Consortium Database (https:// www.pahdb.mcgill.ca). Although most of these mutations are detectable by sequence analysis, with a detection rate of $95 \%$, large intragenic deletions or duplications cannot be identified using this method. In these cases, multiplex ligation-dependent probe amplification (MLPA) can be used as a sensitive and efficient method $[43,44]$.

Pathophysiology of the bone phenotype. Bone complications are seen in early and continuously treated patients [44]. Indeed, most studies on patients with PKU indicate that bone is often affected. However, there are significant gaps in the pathogenetic basis of this complication neither consensus exists on the degree and implications of bone abnormalities and the risk factors for low BMD [4, $5,14]$. To investigate these gaps, a meta-analysis on BMD, corrected for bias, age and gender, has been performed by Rucker RB et al. [45]. The Authors found that BMD in early diagnosed and treated patients with PKU is below the healthy population average but within the normal range [45]. Moreover, data on a corresponding higher risk of fracture in these patients are missing [45].

Other indicators of bone status in early treated patients with PKU are inconclusive due to the small number of studies and the heterogeneity in the groups examined and in the measurement methods. A recent meta-analysis found that low BMD does not seem to be an exaggerated concern in patients with PKU, and that research is needed on the effects of the PKU diet on bone, on the reliability of bone turnover markers in bone assessment, and on a concrete estimate of fracture risk in patients with PKU [45].

Therapy Dietary treatment is the basis of PKU management. It consists of 3 components: natural protein restriction, Phe-free-L-amino acid supplements, and low protein food intake. Effectiveness of PKU treatment is demonstrated by any of the following objective measures: reduction in Phe blood concentrations, increase in natural protein tolerance, improvement in neuropsychological testing, in the nutritional status, and in the quality of life [46]. A possible enzyme replacement therapy using PEG Phenylalanine-Ammonia Lyase (PAL) or Pegvaliase is under investigation [46]. PEG-PAL trials have proven short-term reduction in the Phe blood concentrations in adult PKU patients, but further studies are required to observe long-term effectiveness and safety. Results of a phase III extension study (NCT01819727) are awaited. Gene therapy and therapeutic liver repopulation have been investigated in murine models only, and larger animal PKU models and human studies need to be developed [46].

Table $1 \mathrm{C}$ describes the diseases due to the alteration of tyrosine pathway in which the skeletal involvement has been described.

\section{Liver rare diseases \\ Disorders of copper metabolism}

Under the liver rare diseases we selected the diseases with a main impact on bone, being the ones characterized by disorders of Copper metabolism.

\section{Description of the systemic disease}

Copper $(\mathrm{Cu})$ has an essential role in the normal maturation of collagen, particularly in the important steps of the formation of lysine-derived cross-links [47]. Since 1950, several reviews on $\mathrm{Cu}$ metabolism have contributed to the understanding of the human whole-body $\mathrm{Cu}$ metabolism [48-50]. The reviews generally reached similar conclusions on many aspects of $\mathrm{Cu}$ metabolism [48-50]. Dietary $\mathrm{Cu}$ is absorbed into the body through the intestinal mucosa and transported via the portal blood to the liver, where it is prevalently incorporated into ceruloplasmin, released into the blood, and delivered to tissues. The $\mathrm{Cu}$ uptake into the liver does not appear to be highly regulated. In contrast, the export of $\mathrm{Cu}$ from the liver is a regulated $\mathrm{Cu}$-dependent process, which is mediated by a $\mathrm{Cu}$-transporting $\mathrm{Cu}$-ATPase ATP7B. $\mathrm{Cu}$ is exported from the enterocytes into the blood by $\mathrm{Cu}$-ATPase ATP7A in a process that involves trafficking of the transporter towards the baso-lateral membrane [51]. Details of these mechanisms and cellular metabolism are covered in Fig. 2.

In humans, $\mathrm{Cu}$ is characterized by very low storage in the body $(<100 \mathrm{mg})$ compared with other trace elements such as zinc and iron [48]. The highest $\mathrm{Cu}$ concentration is in the liver, followed by the brain, kidney and heart [48]. Several conditions and disorders influence wholebody $\mathrm{Cu}$ metabolism, including metabolic defects, such as Menkes syndrome and Wilson disease, pregnancy, inflammation, and numerous other diseases [48]. Blood concentrations increase dramatically in many of these conditions and several tissues, including bone, are damaged by this dysregulation.

\section{Menkes diseases}

Genetic defects The physiological importance of $\mathrm{Cu}$ ATPases in humans can be illustrated by the deleterious consequences of the $\mathrm{Cu}$-ATPase inactivation on cell metabolism. Mutations or deletions in the ATP7A gene 


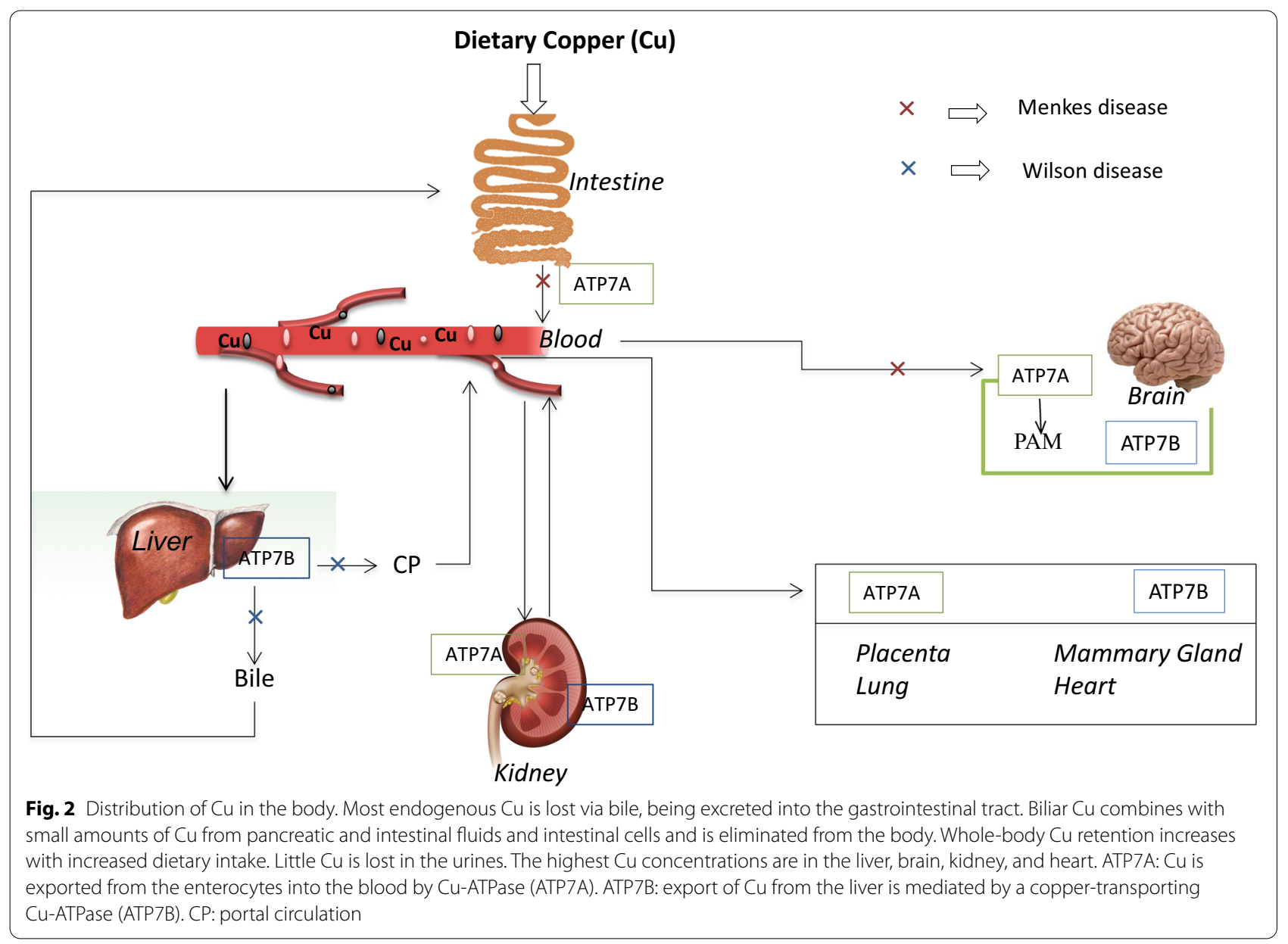

encoding the $\mathrm{Cu}$-ATPase ATP7A are associated with a fatal childhood disorder, Menkes disease. The Menkes gene is located on the long arm of the $\mathrm{X}$ chromosome at $\mathrm{Xq13.3}$, and the gene product, ATP7A, is a 1500-amino acid P-type adenosine triphosphatase (ATPase) that has 17 domains -6 copper binding, 8 transmembrane, a phosphatase, a phosphorylation, and an ATP binding. The lack of functional ATP7A is associated with severe connective tissue defects in Menkes disease patients, likely due to disrupted delivery of $\mathrm{Cu}$ to lysyl oxidase in the secretory pathway. The connective tissue defects, including vascular tortuosity, loose skin, hyperextensible joints and bone fragility, are commonly observed in Menkes disease [48].

Pathophysiology of bone phenotype $\mathrm{Cu}$ has an essential role in the normal maturation of collagen, particularly in the important steps to the formation of lysine-derived cross-link skeletal findings in infants with Menkes disease, the most characteristic of which are metaphyseal spurs, long-bone fractures, and wormian bones [52-54]. The long-term findings have been described by Ama- dor et al. [52] and differ completely from those initially observed. In particular, undertubulation and metaphyseal flaring, similar to the findings seen in some types of bone dysplasia, are present [52]. In addition, the defective collagen cross-linking leads to osteoporosis and pathological fractures in these children $[53,54]$.

\section{Therapy}

Ceruloplasmin, the circulatory blue $\mathrm{Cu}$ protein, possesses antioxidant, cardioprotective and neuromodulatory properties. So far, subcutaneous $\mathrm{Cu}$-histidine supplementation is the current choice of therapy, and long-term administration is not desirable because of the expected nephrotoxicity. Recently, a patient affected by Menkes disease was treated with weekly intravenous $\mathrm{Cu}$-chloride and tolerated the procedure well with no major adverse events. However, optimum management of long-term survival of classical Menkes disease patients is currently unknown and a closed follow-up is mandatory for clarification of this phenotype [55]. Esmaeili et al. [56] described the preparation and characterization of 
four low molecular weight copper complexes, with special emphasis given to aspects related to the stability of these complexes in physiologically relevant media, to their potential antioxidant activity and to their biocompatibility with neuronal cells in view of a possible use in the treatment of neurological diseases. Furthermore, the study of these complexes may help to improve chelation therapy for $\mathrm{Cu}$ dysfunctions and to better understand $\mathrm{Cu}$ metabolism in humans [56].Changes in bone mineral density following pamidronate treatment have been described with $34-55 \%$ and $16-36 \%$ increases in lumbar spine bone mineral content and areal mineral density, respectively [54].

\section{Wilson disease}

Genetic defects Mutations in the gene encoding the $\mathrm{Cu}-$ ATPase ATP7B also result in a severe metabolic disorder, known as Wilson disease (WD), which is inherited in an autosomal recessive manner. The $A T P 7 B$ gene is approximately $80 \mathrm{~Kb}$, located on human chromosome 13, and consists of 21 exons. The mRNA transcribed by the $A T P 7 B$ gene encodes a protein of 1465 amino acids [57]. This protein is part of the P-type ATPase family, a group of proteins that transports metals into and out of cells by using energy stored in the molecule adenosine triphosphate (ATP). Cu-transporting ATPase 2 is found primarily in the liver, with smaller amounts in the kidneys and in the brain. WD is caused by various mutations in the $A T P 7 B$ gene. In Western populations, the H1069Q mutation is present in $37-63 \%$ of cases, while in China this mutation is very uncommon and R778L is found more often. Ten percent of patients have no detectable mutations in the ATP7B gene [58].

Pathophysiology of the bone phenotype Skeletal changes have been reported in WD, including osteoporosis $[59,60]$. It is typically associated with an accumulation of $\mathrm{Cu}$ in various tissues, including bone tissue, with skeletal $\mathrm{Cu}$ content reported to be increased by about four times [60]. In a study by Hegedus et al., betacross-laps, a marker of bone remodeling, were found to be significantly increased in WD patients, suggesting increased bone resorption as a key mechanism contributing to bone loss and osteoporosis in these patients [61]. Weiss et al. [59] showed that the severity of liver disease is unrelated to the degree of bone loss as assessed by DXA, hypothesizing that $\mathrm{Cu}$ accumulation may directly affect bone metabolism. Indeed, accumulation of $\mathrm{Cu}$ causes production of reactive oxygen species (ROS) which is a risk factor for osteoporosis and may accelerate the effect of aging of bone by stimulating osteoclast differentiation and bone resorption and inhibiting osteoblast differentiation $[59,62]$.
In addition, an excess of $\mathrm{Cu}$ is able to induce mitochondrial dysfunction and mitochondrial toxicity, which are causally related to bone demineralization [59].

Therapy In guidelines for the American Association for the Study of Liver Diseases, medical therapy is divided into 2 categories: treatment of symptomatic patients and treatment of asymptomatic patients [63]. Treatment of symptomatic patients (hepatic, neurologic, or psychiatric) should include chelation therapy, either with D-penicillamine or with trientine that increases urinary $\mathrm{Cu}$ excretion. Patients with WD are counseled to eat a diet low in $\mathrm{Cu}$ and avoid the very high $\mathrm{Cu}$ foods, such as mushrooms, chocolate, liver, and nuts [63]. Studies with sodium tetrathiomolybdate for the treatment of WD suggested some benefit for its use as initial treatment of patients with neurological complications [63]. A phase 2 study was conducted with a more stable form of a chelator for $\mathrm{Cu}$, the choline tetrathiomolybdate (WTX101) molecule, that has the potential to increase biliary $\mathrm{Cu}$ excretion as well as bind $\mathrm{Cu}$ and albumin in an inert complex $[64,65]$. Liver transplant can be used to rescue those with acute liver failure or those with liver disease who fail to respond to medical therapy. New advances in treatment may improve adherence and reduce some complications of treatment $[64,65]$.

Table 2 describes the liver diseases due to the alterations in the $\mathrm{Cu}$ metabolic pathway.

\section{Respiratory rare disease}

\section{Description of the systemic disease}

Rare lung diseases comprise many disorders and are described in more detail in the recent Orphan Lung Diseases Taxonomy by the European Respiratory Society [66]. In the present paper we describe cystic fibrosis, as the most relevant rare lung disease with an impact on bone metabolism.

\section{Cystic fibrosis}

Cystic fibrosis is an inherited disease characterized by the buildup of thick, sticky mucus that can damage many of the body's organs. The disorder's most common signs and symptoms include progressive damage to the respiratory system and chronic digestive problems. The features of the disorder and their severity varies among affected individuals [67].

Genetic defects Mutations in the cystic fibrosis transmembrane conductance regulator (CFTR) gene cause cystic fibrosis [68]. The CFTR gene is localized on chromosome $7 \mathrm{q} 31.2$ and provides instructions for making a 
channel that transports negatively charged particles called chloride $(\mathrm{Cl})$ ions into and out of the cells [69].

$\mathrm{Cl}$ is a component of sodium chloride, a common salt found in sweat, but it also has important functions in cellular metabolism, as the flow of $\mathrm{Cl}$ ions helps to control the movement of water in tissues [69]. Mutations in the CF transmembrane conductance regulator (CFTR) gene disrupt the function of the $\mathrm{Cl}$ channels, preventing them from regulating the flow of $\mathrm{Cl}$ ions and water across cell membranes. As a result, living cells in lungs, pancreas and other organs produce mucus that is unusually thick and sticky [69-71].

Pathophysiology of the bone phenotype Major pathogenic mechanisms mediating the development of $\mathrm{CF}$ bone disease (CFBD) in patients with CF may result from a combination of episodes of low bone turnover and formation rate during periods of disease stability, and an increased bone turnover and resorption during infective exacerbations [72]. Osteoporosis and increased vertebral fracture risk have been associated with CF disease, becoming more relevant with the increase in life expectancy of these patients. The first report on association of low BMD with CF was published in 1979 [71]. The etiology of low bone density is multifactorial, most probably a combination of inadequate peak bone mass during puberty and increased bone loss in adults [72]. Body mass index, male sex, advanced pulmonary disease, malnutrition and chronic therapies are established additional risk factors for CFBD [72]. Fractures not only cause pain and disability, but vertebral fractures and kyphosis further impair breathing biomechanics and often disqualify a patient from lung transplantation [73, 74]. Stalvey et al. developed and showed a CF disease model in which CFTR expression in bone directs reduced osteoblast differentiation and enhanced osteoclastic bone resorption [73]. This report, and other studies, demonstrate that CFTR is expressed in mesenchyme-derived osteoblasts, odontoblasts, chondrocytes and myocytes, and that mutations directly perturb cellular activities of these cell types $[75,76]$. The in vitro evidence of delayed osteoblast new bone formation, and enhanced osteoclastic bone resorption resulting from reduced osteoprotegerin expression parallels the uncoupled bone turnover that is characteristic of CFBD in humans and in animal models $[77,78]$. In addition, in human osteoblasts obtained from a 25-year-old CF male with the F508del/G542X mutation in the CFTR gene, a defective CFTR-mediated Cl-channel activity and a severe deficit in the production of osteoprotegerin was described $[77,78]$. These data raised the hypothesis that the Cftr gene may play a role in cell differentiation and bone matrix maturation [79].
Therapy The goals of treatment primarily include: 1 . preventing and controlling lung infections; 2. controlling of airway inflammation; 3 . reducing viscoelasticity by removing thick, sticky mucus from the lungs and dilating the airways A new group of drugs called CFTR modulators are available which are able to correct the basic defect in $\mathrm{CF}$, with an improvement in the management of the disease $[75,80]$. However, most of these drugs are having serious hepatic and extra-hepatic side effects, in addition to high costs. Gene engineering techniques and new molecular targets may be explored besides CFTR. With the help of modern biology approaches like DNA nanotechnology, systems biology, metabolomics, disease modeling, and intracellular protein kinetics new pathways and networks associated with CF can be unraveled and eventually new therapeutic targets can become available [80, 81].

Table 3 describes the phenotypic characteristics of cystic fibrosis.

\section{Hematological rare disoders \\ Description of the systemic disease}

Rare blood disorders include various myeloproliferative diseases (also called myeloproliferative neoplasms), as well as histiocytosis and paroxysmal nocturnal hemoglobinuria (PNH). There are several kinds of myeloproliferative disease, including polycythemia vera, myelofibrosis, essential thrombocythemia, mastocytosis, and eosinophilia [82]. In a seminal paper Teti A. et al. described congenital bone diseases and their relationship to hematopoietic tissue [83]. Some of these diseases affect primarily the bone tissue and may have hematological alterations. These disorders have been also previously described by our group in the taxonomy of the rare metabolic skeletal diseases [3]. Here, we take in consideration the congenital hematological disorders that can be associated to a modification of bone turnover. They are represented by mastocytosis, beta-thalassemia, hemophilia type A and B, sickle cell disease, Ghosal hematodiaphyseal dysplasia, severe congenital netropenia, and histiocytosis.

\section{Mastocytosis}

Description of the systemic disease Mastocytosis is a complex disorder characterized by the accumulation of abnormal mast cells (MCs) in the skin, bone marrow and/ or other visceral organs. The clinical manifestations result from MC-derived mediators and, less frequently, from destructive infiltration of MCs. Patients suffer from a variety of symptoms, including pruritus, flushing and lifethreatening anaphylaxis. While mastocytosis is likely to be suspected in a patient with typical skin lesions (i.e. urticaria pigmentosa [UP]), the absence of cutaneous signs 
does not rule out the diagnosis of this disease. Mastocytosis should be suspected in cases of recurrent, unexplained or severe insect-induced anaphylaxis or symptoms of MC degranulation without true allergy [84].

In rare cases, unexplained osteoporosis or unexplained hematological abnormalities can be the underlying features of mastocytosis, particularly when these conditions are associated with elevated baseline serum tryptase levels. The diagnosis is based on the World Health Organization (WHO) criteria, in which serum tryptase levels, histopathological and immunophenotypic evaluation of MCs and molecular analysis are crucial [85]. The WHO classification subdivides mastocytosis into seven major categories: (1) cutaneous mastocytosis, (2) indolent systemic mastocytosis, (3) systemic mastocytosis with associated clonal, hematological non-mast-cell lineage disease, (4) aggressive systemic mastocytosis, (5) mast cell leukemia, (6) mast cell sarcoma, and (7) extracutaneous mastocytoma. Within these major categories additional variants and subvariants coexist, some of which are currently considered 'provisional entities' [85].

Genetic defects Mastocytosis is associated with a somatic gain of function point mutation in the KIT gene. This was firstly recognized in 1995, when Nagata et al. [86] identified a point mutation in exon 17 , resulting in a substitution of valine for aspartic acid in the catalytic domain of the KIT gene (D816V) in the peripheral blood of four patients with mastocytosis. Further analysis of larger cohorts confirmed that the KIT gene D816V mutationis detected in up to $93 \%$ of adult patients with the disease [84]. By contrast, patients with childhood onset mastocytosis may not have detectable KIT mutations or may express KIT mutations other than D816V (in exons 8, 9, 11 or 17) [84].

Pathophysiology of the bone phenotype Osteopenia/osteoporosis with bone pain and possible pathological fractures has long been recognized in systemic mastocytosis (SM) patients. Half of adult patients with SM show bone involvement. Osteoporosis is the most prevalent bone manifestation in SM (31\%) [87]. Serum Interleukin 6 (IL6) is elevated in mastocytosis patients and correlates with severity of symptoms and the presence of osteoporosis. High serum IL-6 may not only signify disease progression, but may also participate in the pathophysiology of $\mathrm{SM}$. The pathological fractures are considered a marker of aggressive SM, especially when associated with high levels of serum tryptase [84]. The main actor is the osteoclast with a relative or absolute predominance of bone resorption versus formation. Among the stimuli that drive osteoclast activity, the most important is the Receptor Activator of Nuclear Factor א B (RANK)-RANK-Ligand (RANKL) signaling, but also histamine and other cytokines play a significant role in the process [84].

Therapy During the last two decades, major discoveries contributed to a better diagnosis, identification of the clinical and biological abnormalities, and a refined classication of the different forms of mast cell disease [84]. Various cytoreductive treatments have been used for advanced SM, including 2-chlorodeoxyadenosine (2-CDA), interferon-alpha (IFN- $\alpha$ ), classical chemotherapy agents (such as cytarabine or udarabine), but all with modest and disappointing response rates, highlighting the need for innovative therapies [84]. Tyrosine kinase inhibitors (TKIs) are an attractive therapeutic approach, given the pathogenesis of SM and the involvement of KITD816V mutation in more than $80 \%$ of patients, and other KIT mutations that map to the TK juxtamembrane domain or transmembrane domain in sporadic cases of SM. Many studies have reported quantitative and qualitative defects of signal transduction in SM [88]. These altered pathways play a role in the pathogenesis of SM and targeted drugs may provide therapeutic options by selective inhibition of some of these critical targets. Finally, normal and neoplastic mast cells express on their surface a number of cell surface antigens that might be considered as potential targeted therapies in advanced SM [88]. The central role of osteoclasts made bisphosphonates, as anti-resorptive drugs, the standard of treatment for bone involvement in SM [89]. Bisphosphonate therapy seems to improve lumbar spine BMD during SM-related osteoporosis. Spine $\mathrm{x}$-ray and BMD should be performed in all SM patients to detect those who may benefit from an osteoporosis therapy [89].

\section{Thalassemia}

Description of the systemic disease Thalassemia is an inherited blood disorder characterized by a defect in the globin chain synthesis in red blood cells. The clinical phenotype results from both the diminished amount of the particular globin chain as well as from the resultant chain imbalance that occurs because of normal production of the other globin chain [90]. The common forms include alpha $(\alpha)$ and beta $(\beta)$ thalassemia [90]. In $\beta$ thalassemia, the synthesis of normal $\alpha$ globin chains from the unaffected $\alpha$ globin genes continues as normal, resulting in the accumulation within the erythroid precursors of excess unmatched $\alpha$ globin [91]. In $\alpha$ thalassemia many mutations can affect the $\alpha$ globin gene, but the most common are gene deletions [91]. Anemia in $\beta$ thalassemia results from a combination of ineffective erythropoiesis, peripheral hemolysis, and an overall reduction in hemoglobin synthesis. The severity of disease in $\beta$ thalassemia correlates well with the degree of imbalance between $\alpha$ and 
non- $\alpha$ globin chains and the size of the free $\alpha$ chain pool. Thus, factors that reduce the degree of chain imbalance and the magnitude of $\alpha$ chain excess in the red cell precursors will have an impact on the final phenotype [91]. It might be important to note that the clinical phenotype becomes most apparent at 6-9 months of age, due to the fetal to adult hemoglobin switch that occurs at that age [90]. Finally, $\beta$ thalassemia is the only form of this disorder where bone metabolism is involved.

Genetic defects Thalassemia results when mutations affecting the genes involved in hemoglobin $(\mathrm{Hb})$ biosynthesis lead to decreased $\mathrm{Hb}$ production. Depending on the mutation of genes located on chromosome 16 and 11 we can distinguish $\alpha$ and $\beta$ thalassemia, respectively [90]. Mutations in the $H B B$ gene cause $\beta$ thalassemia. The $H B B$ gene provides instructions for making beta-globin a subunit of hemoglobin. Some mutations in the $H B B$ gene prevent the production of $\beta$ globin [91]. About 100 mutations have been described that decrease $\beta$ chain synthesis. Mutations fall into two classes: B0 refers to mutations that cause no $\beta$ globin to be produced and $\mathrm{B}+$ describes mutations that result in a diminished but not absent quantity of $\beta$ globulin. The severity of these mutations can vary depending on the amount of normal $\beta$ globin that is produced [91]. Depending the class of mutation present and the gene dosage (i.e. heterozygous or homozygous), patients can present with different severity of the disease [90]: (a) $\beta$ thalassemia major (TM) refers to a severe clinical phenotype; (b) $\beta$ thalassemia intermedia is characterized by a clinical phenotype based on heterogenous genetic mutations that still allow for some $\beta$ chain production (e.g. $\mathrm{B}+/ \mathrm{B} 0, \mathrm{~B}+/ \mathrm{B}+$ ); and (c) $\beta$ thalassemia minor/ thalassemia trait shows a mild clinical phenotype with a normal copy of the $\beta$ globin gene being present (e.g. $\mathrm{B}+/ \mathrm{B}, \mathrm{B} 0 / \mathrm{B})[90]$.

Pathophysiology of the bone phenotype Metabolic bone disease represents a major cause of morbidity in patients with TM (the most severe form). The pathogenic factors include: the primary disease itself that causes bone marrow expansion, the chronic anemia, and the iron endocrine toxicity $[92,93]$.

Marrow expansion causes mechanical interruption of bone formation, leading to cortical thinning and increased distortion and fragility of the bone [93]. Other factors lead to alterations in the RANK/RANKL/ osteoprotegerin system, increasing osteoclastic activity and enhancing osteoblast dysfunction [94, 95]. The increase of RANKL, followed by unmodified osteoprotegerin levels, with the consequent increase of RANKL/ osteoprotegerin ratio, may represent the cause of the uncoupling of bone turnover observed in thalassemia patients. However, no correlation between sRANKL or osteoprotegerin levels with BMD of the lumbar spine or at the femoral neck is present [93].

Hypogonadotrophic hypogonadism and delayed puberty are the most common endocrine complications in patients with TM, and they also contribute to osteopenia and osteoporosis. Morabito et al. [96] showed a negative correlation between RANKL and free testosterone in male thalassemia patients and with $17 \beta$-estradiol in female thalassemia patients, which suggests that a reduced production of sex steroids causes an increase in RANKL production [96]. There are gender differences not only in the prevalence but also in the severity of the osteoporosis syndrome. The reported frequency of osteoporosis, even in well-treated TM patients, varies from $13.6 \%$ to $50 \%$ with an additional $45 \%$ affected by osteopenia [92]. The lack of an anabolic effects of growth hormone $(\mathrm{GH})$ and insulin-growth factor I (IGF-1) on bone formation for the acquisition of bone mass, mainly during childhood and puberty, is clearly involved in the pathogenesis is of bone mass reduction in thalassemic patients.

Therapy Transfusion therapy works by supplying normal erythrocytes and suppressing ineffective erythropoiesis, essentially controlling all downstream pathophysiological mechanisms in thalassemia. Whether iron overload develops from increased intestinal absorption or secondary to regular transfusions, it can cause substantial morbidity and mortality, and so warrants prompt diagnosis and effective management. For this reason it is important to use iron chelators in the affected patients. Three iron chelators are currently available for the treatment of iron overload in patients with thalassemia: deferoxamine, deferiprone and deferasirox. Finally, splenectomies have traditionally been performed as an alternate or adjunct therapy to transfusion [93]. In TM, GH secretory dysfunction is common and contributes to osteopenia and osteoporosis, along with other endocrinopathies, such as hypoparathyroidism, vitamin D deficiency, hypothyroidism, and diabetes [94]. Prevention is without a doubt the first step in the management of osteoporosis in TM, with the final goal of preventing bone fragility and fractures. The management of patients with TM should start as early as at birth in order to minimize disease complications [85-94].

Figure 3 shows the mechanisms responsible for the pathogenesis of thalassemia.

\section{Hemophilia}

Description of the systemic disease Hemophilia is a male bleeding disorder with worldwide distribution. Affected 


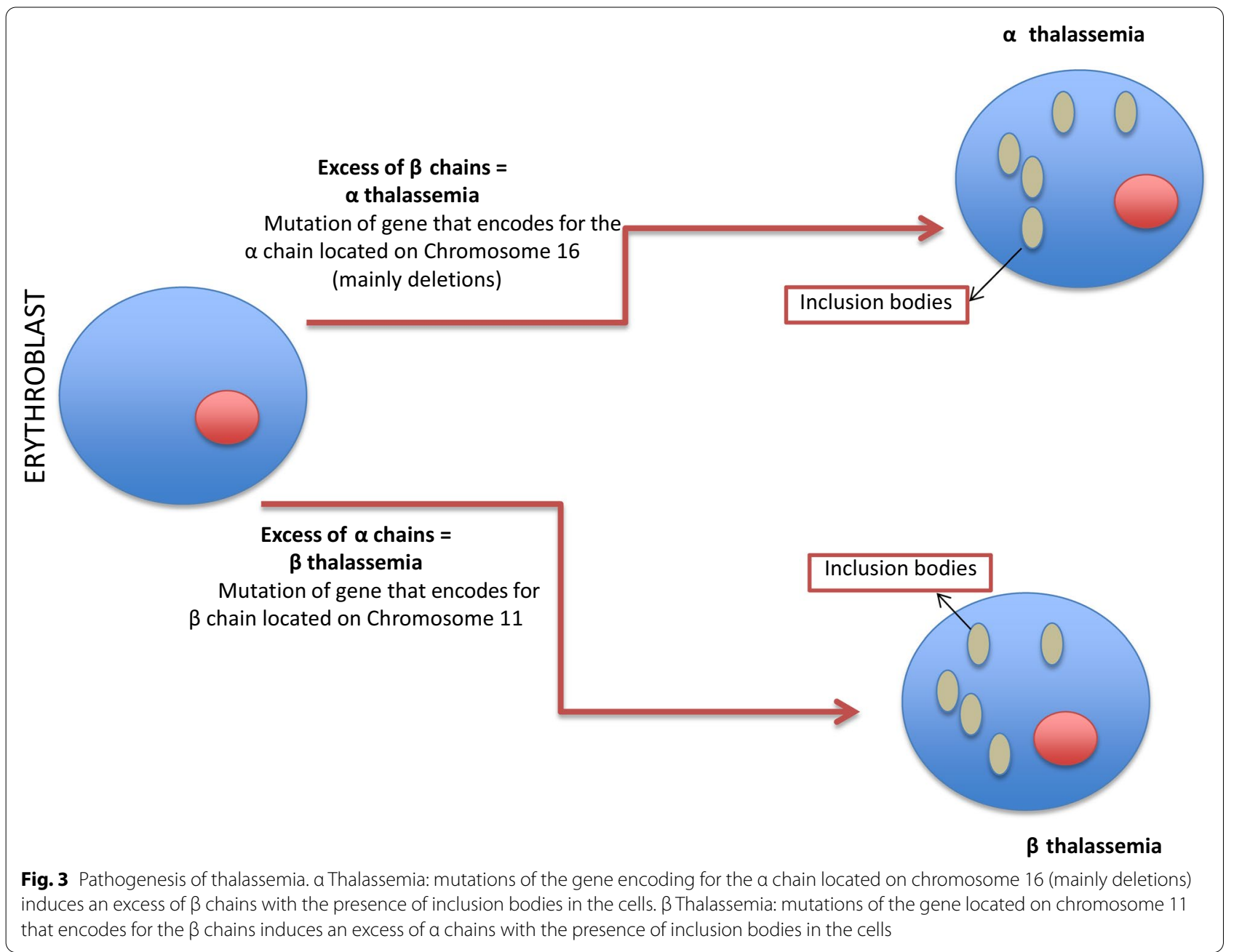

individuals have either reduced or absent levels of coagulation factor VIII and IX in plasma (hemophilia A and hemophilia B respectively). Hence, they encounter unusual bleeding, either spontaneous or after trauma and surgery. The spectrum of bleeding manifestations varies from superficial ecchymosis to lethal hemorrhage in the central nervous system $[97,98]$. While the prevalence of hemophilia A varies among different countries, its prevalence has been estimated to be about 3 to 20 per 100,000 in the population. Hemophilia B is seen as 1 case among 5,000 male births in European countries and the United States $[97,98]$. Individuals with hemophilia A and B have respectively either reduced or absent levels of coagulation factor VIII and IX. Lack or reduced levels of coagulation factors VIII and IX result in impaired clot formation and tendency to bleeding episodes. These lifelong disorders are categorized as severe type $(<1 \%)$, medium type (1-5\%), and mild type (5-30\%) [98]. Replacement therapy using plasma derived or recombinant coagulation factor concentrates are the basis of treatment for bleeding episodes and prophylaxis regimens [99].

Genetic defects A X-linked, recessive hemorrhagic trait or gene induces Hemophilia A. Hemophilia A X-linked trait manifests as a congenital absence or decrease in plasma clotting Factor VIII, a pro-coagulation cofactor and robust initiator of thrombin that is essential for the generation of adequate amounts of fibrin to form a platelet/fibrin plug at sites of endothelial disruption. Female hemophilia gene carriers do not manifest symptoms of Hemophilia A but may have lower than usual quantities of Factor VIII. Male Hemophilia A patients do not transmit hemophilia to male offspring, but all their female offspring will carry the hemophilia gene.

Pathophysiology of the bone phenotype Twenty-seven percent of hemophilic patients have osteoporosis and 43\% osteopenia [92]. A large and growing body of literature has investigated osteopenia and osteoporosis both in chil- 
dren and in adults with hemophilia [98, 100, 101]. While physical activity is considered as a central indicator of bone resorption, patients with bleeding disorders are less likely to engage in high impact activities and weight-bearing exercises [98]. . Hemarthrosis, infection with hepatitis $\mathrm{C}$ virus are also commonly reported causes of susceptibility of hemophilia to reduced bone density [98]. Recently, a survey in hemophilia A, hemophilia B and von Willebrand disease (vWD) showed a higher risk of bone health outcomes in comparison with healthly controls and suggested a possible role of endogenous coagulation factors in the maintainanceof bone mass [102].

Therapy The first successful treatment of hemophilia A with whole blood transfusion was reported in 1840 and subsequently, treatment with plasma was introduced, with the cryoprecipitate fractions of plasma enriched in FVIII firstly utilized in 1964 [97]. High purity Factor VIII concentrate treatment started in 1984 with the production of recombinant FVIII (rFVIII) generated through cloning of FVIII [103]. The development of recombinant FVIII (rFVIII) infusion has improved the life expectancy of patients with mild to moderate hemophilia A, reaching levels comparable to that of the general population. However, an ongoing concern is the development of inhibitory antibodies to plasma-derived FVIII or rFVIII. Prophylaxis appears to be used less frequently in hemophilia B than in hemophilia A patients.

Gene therapy clinical trials for hemophilia $B$, which is caused by the lack of another clotting protein Factor IX are ongoing. A gene therapy is more challenging for hemophilia B in comparison with hemophilia A, because of the molecular properties of FVIII. One of the major obstacles in the development of successful clinical trials of FVIII gene therapy has been the large size of the $F 8$ gene.

Transplantation and engraftment of liver sinusoidal endothelial cells (LSECs) capable of producing FVIII provides the most natural pathway for the cure of hemophilia A. Such a cell based therapy for hemophilia A offers the potential of a life-long cure if a number of hurdles can be overcome. Hemophilia B may have been relatively neglected compared to haemophilia $\mathrm{A}$, but of note, major recent advances in haemophilia therapy (i.e. longer-acting factor concentrates with extended half-lives, and gene therapy) will potentially be available for haemophilia B before haemophilia A [104, 105]. For bone health, the results of a study on the effect of prophylaxis in hemophilia indicated that replacement therapy as a prophylaxis regimen beginning in early childhood may preserve normal BMD in severe hemophilia patients [106].

\section{Sickle cell disease}

Description of the systemic disease Sickle cell disease (SCD) is an inherited disorder of hemoglobin $(\mathrm{Hb})$ synthesis affecting many individuals throughout the world. SCD manifests itself soon after the protective effect of $\mathrm{HbF}$ diminishes. Its complications vary: acute chest syndrome, proliferative retinopathy, pulmonary hypertension, renal insufficiency, cerebral vascular accident, and musculoskeletal complications [107]. SCD is classified by the number of globin genes that are affected and inherited in an autosomal recessive manner. The heterozygous form is when the individual only carries one gene for $\mathrm{HbS}$ and is called sickle cell trait. It occurs frequently in individuals of African ancestry with $8 \%$ to $10 \%$ of African Americans carrying the trait. This is benign and the affected individual will not show any symptoms and no treatment or precautions are needed. The homozygous state is the most common and severe form of SCD and is called sickle cell anemia (HbSS), accounting for $60-70 \%$ of SCD in the United States (US). In HbSS, the red blood cells are distorted and sickle shaped [107]. The two major characteristics are chronic hemolytic anemia and intermittent vasoocclusion that results in tissue ischemia and causes acute, severe pain episodes. SCD is a chronic disease that has detrimental effects on the entire body [107].

Genetic defects SCD encompasses a group of disorders characterized by the presence of at least one hemoglobin S allele ( $H b S$; p.Glu6Val in $\mathrm{HBB}$ ) and a second $\mathrm{HBB}$ pathogenic variant resulting in abnormal hemoglobin polymerization. $\mathrm{HbS} / \mathrm{S}$ (homozygous p.Glu6Val in $\mathrm{HBB}$ ) accounts for $60-70 \%$ of SCD in the United States. Other forms of $\mathrm{SCD}$ result from coinheritance of $\mathrm{HbS}$ with other abnormal $\beta$ globin chain variants. SCD is inherited in an autosomal recessive manner. If one parent is a carrier of the $\mathrm{HBB} H b S$ pathogenic gene variant and the other is a carrier of any of the HBB pathogenic variants (e.g., $\mathrm{HbS}$, $\mathrm{HbC}, \beta$ thalassemia), each child has a $25 \%$ chance of being affected, a 50\% chance of being an unaffected carrier, and a $25 \%$ chance of being unaffected and not a carrier. Prenatal diagnosis for pregnancies at increased risk for SCD is possible by molecular genetic testing if the HBB pathogenic variants have been identified in the parents [107].

Pathophysiology of bone phenotype The bone involvement in SCD ranges from acute manifestations, such as painful vaso-occlusive crisis or osteomyelitis, to more chronic and debilitating complications, such as osteonecrosis, osteoporosis and osteopenia, impaired growth and chronic infections [107]. Although these bone complications may not contribute directly to mortality, they are the major source of morbidity with a high impact on patients' quality of life [107]. Osteopenia and osteoporo- 
sis are often asymptomatic but may cause pain, fractures, deformity, and vertebral collapse [107-109].

Serrai et al. [110] observed a high prevalence (76\%) of abnormal BMD (low and very low) by DXA in SCD adults, with predilection for the lumbar spine, and they found a strong correlation between low $\mathrm{Hb}$ level and abnormal BMD [110]. Chronic and severe anemia places a burden on the bone marrow, with increased erythropoiesis causing hyperplasia of the bone marrow, decrease in the trabecular network, osteopenia and bone destruction [110]. In addition, various micronutrient and macronutrient deficiencies leading to delayed skeletal maturation (malnutrition, vitamin D and zinc deficiency, etc.), hormonal deficiency (reduced GH, hypogonadism), and poor weight bearing because of chronic pain and inactivity, may all contribute to the development of sickle bone disease $[108,109]$. Over $70 \%$ of adults with SCD will develop low BMD, which typically occurs 2-3 decades earlier (median age 30 years) than in the general population [108].

Therapy Hematopoietic stem cell transplantation has the potential to establish normal erythropoiesis with stable long-term engraftment, amelioration of symptoms, and stabilization of organ damage. Early results in gene therapy for SCD are encouraging. Evaluation of the longterm benefits of curative therapies for SCD requires comparative clinical trials and studies of late effects of transplantation [111].

\section{Ghosal type hemato-diaphyseal dysplasia}

Description of the systemic disease Ghosal hematodiaphyseal dysplasia is a rare inherited condition characterized by abnormally thick bones and a shortage of red blood cells [112]. It is an autosomal recessive disorder characterized by metadiaphyseal dysplasia of the long bones and defective hematopoiesis due to fibrosis or sclerosis of the bone marrow [112]. The disease was described for the first time by SP Ghosal in five children who had moderate to marked anemia and diaphyseal dysplasia [112]. Hematologic manifestations of the syndrome include varying degrees of anemia, thrombocytopenia, or pancytopenia [112]. Only a few cases have been reported in the medical literature. Most affected individuals have been from the Middle East and India. Treatment consists of steroid therapy and most cases reported in literature previously required a low-dose maintenance therapy throughout life to keep hemoglobin at normal levels [112].

Genetic defects Ghosal hematodiaphyseal dysplasia results from mutations in the thromboxane synthase TBXAS1 gene localized on chromosome $7 \mathrm{q} 34$. This gene encodes thromboxane-A-synthase, an enzyme which produces thromboxane A2(TA2). TA2 is responsible for platelet aggregation (via the arachidonic acid cascade) and also modulates bone mineral density variation (by influencing the expression of TNFSF11 and TNFRSF11B, which encode RANKL and osteoprotegerin in osteoblasts, leading to bone sclerosis). Most reported mutations in the TBXAS1 gene are of missense type and the pathogenesis of the bony and hematological abnormalities are presumed to be due to a sclerosing bone dysplasia secondarily leading to marrow hypocellularity [112].

Pathophysiology of the bone disease and the bone phenotype In a Caucasian patient with two biallelic mutations within the gene TBXAS1 (c.266 T>C; c.989 T> C) bone densitometry revealed increased bone density with Z-score of 4.5, consistent with mild thickening of long bone diaphysis noted via X-ray [113, 114]. Strikingly, the bone marrow biopsy revealed haphazard ossification, immature cartilage formation and thickened trabeculae replacing hematopoiesis within the marrow cavity [112, 113]. TBXAS1 defects decrease TXA2-mediated osteoblast RANKL expression paralleled by elevated production of osteoprotegerin, ultimately inhibiting osteoclast differentiation [113]. In addition, increased PGE2 synthesis may induce inflammation and increase bone density [113]. Similar to the Ghosal type hemato-diaphyseal dysplasia is the Camurati-Engelmann disease, an extremely rare disease characterized by hyperostosis of multiple long bones caused by mutations in the TGFB1 gene. However, in the Camurati-Engelmann disease, only the diaphysis is affected, while both diaphysis and metaphysis are affected in Ghosal type hemato-diaphyseal dysplasia [83].

\section{Therapy No specific therapy exists.}

\section{Severe congenital neutropenia}

Severe congenital neutropenia (SCN) patients are affected by congenital severe neutropenia, with an absolute neutrophil count (ANC) of less than $0.2 \times 10^{9} / \mathrm{L}$ [115]. Bone marrow examination in the majority of cases reveals a maturation arrest of myelopoiesis at the level of promyelocytes, which generally leads to reduced neutrophil counts but increased numbers of atypical promyelocytes. In these patients, the risk of infections such as otitis, gingivitis, skin infections, pneumonia, deep abscesses and septicemia begins in the neonatal period [115]. Furthermore, patients with severe congenital neutropenia have an increased risk of developing leukemia [115]. The prevalence of SCN is estimated to be 3-8.5 cases per million individuals. Prevalence depends on several factors: the success of the mother's pregnancy, the frequency of neonatal deaths from infections or other causes, the pattern of inheritance for the specific genetic 
disorder, and the ascertainment of the diagnosis through measurement of the blood ANC early in life [116].

Genetic defects Demographics play an important part in epidemiology. Worldwide, autosomal dominant disorders seem to be more common, whereas the recessive disorders are usually diagnosed in consanguineous kindreds [115]. Several genes can be involved in severe congenital neutropenia and play a role in the maturation and function of neutrophils, promoting cell survival and response to immune signals. Most patients (about 50\%) harbor mutations of the ELANE gene [83], encoding the neutrophil elastase, while about $10 \%$ of patients instead harbor mutations in the HAX1 gene, encoding the HS1 -associated protein X-1 (HAX1), where HS-1 is a Src family tyrosine kinase substrate and HAX1 is a mitochondrial protein that regulates apoptosis [83]. HAX1 protein contributes to the activation of the granulocyte colonystimulating factor (G-CSF) signaling pathway and could cause osteopenia enhancing bone resorption [83]. Various other genes, including CSF3R, G6PC3, GFI1, JAGN1, TCIRG1, VPS45 and WAS, account for a small portion of patients, while about $30 \%$ have unknown genetic defects, with some cases with no familial history, thus classified as sporadic [117]. The GFI1 gene encodes a transcription factor that controls human stem cells quiescence and osteoblast differentiation, inducing epigenetic changes in the RUNX2 promoter [83].

Pathophysiology of the bone phenotype $\mathrm{SCN}$ is associated with osteopenia in at least $40 \%$ of patients, which can then evolve towards overt osteoporosis. Recurrent infections and diminished physical activity may play a prominent role in decreasing BMD because of increased catabolism and poor nutritional status [116]. On the other hand, exogenous administration and genetically induced overexpression of G-CSF have been related to bone mineral loss in animal studies [116]. On the basis of the evidence that osteoclasts are derived from the monocyte/ macrophage lineage, various hypotheses state that a large group of cytokines and CSFs involved in hematopoiesis, including G-CSF, regulate osteoclast development and activity [108]. The receptor activator of nuclear factor-kB (RANK), the RANK-L, and osteoprotegerin. are important regulators of osteoclastogenesis [116]. Elhasid et al. [118] described a 4-year-old patient who had familial SCN and severe osteoporosis with multiple fractures that presented very low levels of osteoprotegerin with a high RANKL/ osteoprotegerin ratio. This may play an important role in the pathogenesis of osteoporosis in these patients [118].

Therapy No specific therapy is available. The anemia can be treated with oral prednisolone with walking difficulties improvement [86]. Bisphosphonates have been used for the treatment of bone loss [116].

\section{Histiocytosis}

Description of the systemic disease Histiocytoses are a diverse group of hematologic disorders defined by the pathologic infiltration of normal tissues by cells of the mononuclear phagocyte system (MPS). Cells of the MPS have a wide range of morphologic, anatomic and functional characteristics that make classification of this system difficult. The development and differentiation of the cells of the MPS, much like other hematopoietic lineage, is driven by a tightly regulated pattern of gene expression governed by distinctive sets of transcription factors that control cell proliferation and differentiation. As proposed in 1987 [119], histiocytic disorders can be classified into three classes based on the pathologic cells present within the lesions:

- Class I: Langerhans cell histiocytoses and other dendritic cell disorders;

- Class II: non-Langerhans cell histiocytoses primarily consisting of hemophagocytic lymphohistiocytosis;

- Class III: malignant histiocytosis

This system was revised in 1997 by the WHO Committee on Histiocytic/Reticulum Cell Proliferations and the Reclassification Working Group of the Histiocyte Society [120]. The central theme of this reclassification effort consisted of distinguishing the clearly malignant histiocytoses from the remaining subtypes, the so-called "disorders of varied biological behavior" [121].

\section{Langerhans cell histiocytosis (X-Histiocytosis)}

Langerhans cell histiocytosis (LCH) is a group of idiopathic disorders characterized by the presence of cells with characteristics similar to bone marrow-derived Langerhans cells juxtaposed against a backdrop of hematopoietic cells, including T-cells, macrophages, and eosinophils. It is a rare disease of unknown pathogenesis, leading to its high rate of misdiagnosis and missed diagnosis.

$\mathrm{LCH}$ is divided into 3 entities: Letter-Siwe disease, Hand-Schuller-Christian disease, and eosinophilic granuloma [121]. LCH can occur at any age, but mainly in children of 1 through 4 years of age. The incidence of $\mathrm{LCH}$ in adults is $1-2$ cases per million. Most LCH patients are males. The sex ratio (m:f) is $2: 1$ [121]

Genetic defects Somatic mutations in the BRAF gene have been identified in the Langerhans cells of about 
half of individuals with Langerhans cell histiocytosis [119]. Somatic gene mutations are acquired during a person's lifetime and are present only in certain cells. These changes are not inherited. A major breakthrough in the $\mathrm{LCH}$ puzzle came with discovery of recurrent somatic $B R A F \mathrm{~V} 600 \mathrm{E}$ gene mutations in histiocytes in $50 \%$ of $\mathrm{LCH}$ lesions, 13 of which have been validated in multiple subsequent studies [122]. BRAF is a central kinase of the MAPK pathway (RAS/RAF/MEK/ERK) that transduces extracellular signals and regulates critical cellular functions [122]. The V600E mutation results in $R A S$-independent constitutive activation of downstream $M E K$ and $E R K$ [118]. Besides the V600E mutation, single case reports have described additional somatic mutations within the $B R A F$ gene locus (BRAF V600D, BRAF600DLAT), as well as the germline mutation/polymorphism BRAF T599A with potential functional consequences [122].

Pathophysiology of the bone phenotype The skeletal system is the most common site of involvement of Langerhans cell histiocytosis, and in $60-80 \%$ of cases is the only organ system involved. The lesions may be asymptomatic and discovered as an incidental radiographic finding, when symptomatic patients complain pain, swelling and tenderness around the lesion. Systemic symptoms may also be present, including general malaise and, on occasion, fever with leukocytosis $[121,123]$. Makras et al. [124] in a retrospective study examined whether BMD and indices of bone turnover are affected in adult patients with $\mathrm{LCH}$ and whether these patients are at high risk of developing osteoporotic fractures. Their findings are particularly relevant as such patients are probably at high risk of developing osteoporosis due to the secretion of bone resorbing cytokines from the pathological process and the presence of a number of several predisposing factors such as anterior pituitary deficiencies and treatment with glucocorticoids and/or chemotherapy. Indeed, adults with LCH have high serum osteoprotegerin levels and low serum RANKL levels than controls [125]. In addition, RANKL is abundantly expressed in cells of adult LCH lesions from different tissues, especially within inflammatory infiltrates [125] and concomitant nuclear staining of p65 NFKB, is associated with increased RANKL expression, suggesting that RANKL could be directly involved in any lesional cell activation [125].

Therapy LCH has a wide spectrum of clinical presentations and variable outcomes. With current risk-adapted treatments, more than $80 \%$ of patients are cured. However, $30 \%$ to $50 \%$ of patients experience disease recurrence and a significant number of survivors develop neurodegeneration. Treatments aimed at achieving long-term cures with low reactivation rates and that could prevent the development of neurodegeneration need to be developed. Targeted therapies with BRAF or MEK inhibitors offer the possibility of reframing the treatment of $\mathrm{LCH}$ in the near future [126]. Denosumab administration, a RANKL inhibitor, seems a rational treatment strategy in $\mathrm{LCH}$ in order to enhance further endogenous osteoprotegerin action and interrupt the lesional immunological process if RANKL related. Makras P et al. showed that the administration of denosumab in patients affected by adult $\mathrm{LCH}$ resulted in a significant remission of the disease activity at both osseous and nonosseous lesions [127]. The Authors concluded that denosumab could be considered an effective treatment option in adults with multisystem $\mathrm{LCH}$, also exerting a significant analgesic effect on bone lesions $[127,128]$.

\section{Non-Langerhans cell histiocytosis: Erdheim-Chester disease (ECD)}

Erdheim-Chester disease (ECD) is a rare, non-Langerhans histiocytosis described by Jakob Erdheim and William Chester in 1930 [129]. Historically, ECD has been considered a variably aggressive histiocytic disorder of unclear origin with poor response to therapy. However, the identification of the clonal nature of the disorder with at least one therapeutically relevant recurrent oncogenic somatic mutation has reformulated our understanding of the pathogenesis and clinical management of the disease [129].

Identifying distinctive histopathologic findings in the appropriate clinical and radiologic context makes possible to evidence infiltration of typically foamy or lipidladen histiocytes with admixed or surrounding fibrosis [130]. Touton giant cells are often present. At the immunohistochemical staining, ECD histiocytes are positive for CD68, CD163, and Factor XIIIa, and negative for CD1a and langerin (CD207), with positivity for S100 being observed rarely[130]. This differentiates ECD from $\mathrm{LCH}$, where Langerhans cells are positive for CD1a, S100, and langerin [130]. In addition to histological features, the radiographic finding of symmetric diaphyseal and metaphyseal osteosclerosis in the legs is nearly always present in ECD [130].

It is a disease with almost constant bone involvement and an extraosseous involvement only in $60 \%$ of patients [131]. The pattern of extraosseus clinical manifestations is highly variable and may be life-threatening [131].

\section{Genetic defects}

Recent discovery of BRAF (V600E) gene mutations in LCH by Badalian-Very et al. [132] yielded the first identification of a bona fide oncogenic alteration in this disorder. Estimates of $B R A F(\mathrm{~V} 600 \mathrm{E})$ gene mutation frequencies in ECD range between 38 and $68 \%$ in most 
reports, with one recent report suggesting that nearly $100 \%(18 / 18)$ of ECD patients have the mutation if sufficiently sensitive techniques are used [132]. In addition, an oncogenic NRAS (Q61R) gene mutation was identified in an ECD patient, further highlighting the importance of mitogen-activated protein kinase signaling to ECD pathogenesis [132]. To further support the clonal nature of ECD, ECD histiocytes have been found to express a pattern of proinflammatory cytokines and chemokines responsible for local activation and recruitment of histiocytes [132]. Based on these studies, ECD can now be defined as a clonal disordercharacterized by frequent hyperactivation of mitogen-activated protein kinase signaling in which an inflammatory milieu is important in the pathogenesis and clinical manifestations of the disease [132].

Pathophysiology of the bone phenotype The most frequently affected bones are the femur, the tibia and the fibula and, less frequently, the ulna, the radius and the humerus. Bone pain usually manifests around the knees and ankles. Osteosclerosis occurs bilaterally and symmetrically in the diametaphyseal regions of the long bones. While the classical hallmark of the skeletal involvement of ECD is osteosclerosis, mixed sclerotic and lytic lesions have occasionally been described. Conversely, bone lesions found in LCH are lytic rather than sclerotic [133] and this complicates the diagnostic iter. The distribution of sclerotic lesions in ECD differs from that of $\mathrm{LCH}$ in that the latter commonly involves the calvarium, facial bones, proximal limbs, pelvis, and scapula, rather than the distal limbs as in ECD [133].

Therapy For decades, corticosteroids, cytotoxic agents such as vinca alkaloids and immunosuppressive agents (i.e. cyclophosphamide, methotrexate and azathioprine) represented the therapeutic milestone for ECD patients. More recently, interferon (IFN)-based therapy has emerged as a reliable option for ECD patients. Inhibition of BRAF activation by vemurafenib is a highly promising treatment, in particular for its ability to overcome the blood brain barrier. Mutations of BRAF gene result in a conformational change of a serine/threonine-protein kinase that leads to a chronic activation of the RAS-RAFMEK-ERK pathway, therefore accelerating the proliferation of the cells [133]. Intriguingly, the recent discovery of additional NRAS gene mutations in ECD strongly suggests that the entire RAS-RAF-MEK-ERK pathway plays a pathogenic role in histiocytosis, thus raising interest in dual BRAF/MEK inhibition [134]. Improved understanding of the pathogenetic mechanisms underlying ECD will lead to the development of more effective targeted therapies, while an accurate stratification of patients based on their neurologic involvement will help clinicians to maximize the benefits of novel molecular targeting for therapies.

Table 4 describes the hematological disorders with bone involvement.

\section{Neurological rare diseases}

Many neurological and neuromuscular diseases may cause an increase in the risk of osteoporosis and fragility fractures [135]. Although the etiology of osteoporosis is multifactorial (with genetic factors accounting for $70 \%$ of the variability in bone density) exposure to high doses of corticosteroids and poor mobility, conditions typical of some neurological or neuromuscolar diseases, are two important potential causes of bone fragility. In addition, epileptics are a separate group of patients at particular risk of fracture [135]. Here we selected Rett syndrome to describe the costellation of the bone phenotype, that characterizes this disorder neurological in nature.

\section{Rett syndrome \\ Description of the systemic disease}

Rett Syndrome (RS) is a severe neurological disease, characterized by the arrest of brain development. Most individuals with RS express a mutation in the MECP2 gene, which either activates or represses neural transcription when it binds to methylated cytosines in DNA [135, 136]. Clinical outcomes for this syndrome are complex, with varying degrees of autonomic dysfunction [137]. Patients with classic RS appear to develop normally until 6-18 months of age, then gradually lose speech and purposeful hand use, and develop microcephaly, seizures, autism, ataxia, intermittent hyperventilation, and stereotypic hand movements. After this initial regression, the condition stabilizes and patients usually survive into adulthood [137].

\section{Genetic defects}

As RS occurs almost exclusively in females, it has been proposed that it is caused by an X-linked dominant mutation with lethality in hemizygous males $[137,138]$. Previous exclusion mapping studies using RS families mapped the locus to Xq28 [139]. In a systematic gene screening approach, mutations in the $M E C P 2$ gene encoding the X-linked methyl-CpG-binding protein 2 (MeCP2) were recognized as the cause of some cases of RS [140]. MeCP2 selectively binds CpG dinucleotides in the mammalian genome and mediates transcriptional repression through interaction with histone deacetylase and the corepressor SIN3A [140]. 
Table 6 Malformative syndrome

\begin{tabular}{|c|c|c|c|c|c|c|}
\hline Disease & $\begin{array}{l}\text { OMIM } \\
\text { phenotype } \\
\text { number }\end{array}$ & $\begin{array}{l}\text { OMIM gene/ } \\
\text { locus number }\end{array}$ & Gene & $\begin{array}{l}\text { Chromosome } \\
\text { location }\end{array}$ & $\begin{array}{l}\text { Bone phenotype } \\
\text { (specific signs and symptoms) }\end{array}$ & $\begin{array}{l}\text { Bone } \\
\text { biochemical } \\
\text { markers }\end{array}$ \\
\hline $\begin{array}{l}\text { Tricho-rhino-phalangeal } \\
\text { syndrome, typel }\end{array}$ & 190350 & 604386 & TRPS1 & $8 q 23.3$ & $\begin{array}{l}\text { Craniofacial abnormalities and distur- } \\
\text { bances in formation and maturation of } \\
\text { bone matrix. Clinodactyly, phalangeal } \\
\text { epiphyses of the hands appearing as } \\
\text { cone-shaped, short stature, hip joint } \\
\text { malformations, joint pain (late-onset), } \\
\text { osteopenia (late-onset), osteoarthritis } \\
\text { (late-onset), scoliosis, lordosis, coxa } \\
\text { plana, coxa magna, flattened capital } \\
\text { femoral epiphyses, swelling of proximal } \\
\text { interphalangeal joints, short metacar- } \\
\text { pals, short metatarsals, and pes planus, } \\
\text { osteoporosis }\end{array}$ & $N R$ \\
\hline
\end{tabular}

Bone biochemical markers acronyms present in the Tables

BSAP bone specific alkaline phosphatase, NTX corss-linked N-telopeptide of type I collagen, OCN osteocalcin, DPD deoxypyridinoline, PYR pyridinoline, CTX corsslinked C-telopeptide of type I collagen, OPG osteoprotegerin, PTH parathyroid hormone, $25(\mathrm{OH}) \mathrm{D}_{3} 25$ hydroxyvitamin $\mathrm{D}_{3}, \mathrm{~L}$-1 $a$ interleukin 1 alpha, TNF- $a$ tumor necrosis factor alpha, IL-6 Interleukin 6, P1NP Procollagen type $1 \mathrm{~N}$-terminal propeptide

\section{Pathophysiology of the bone phenotype}

RS patients also develop skeletal abnormalities such as scoliosis, low bone density and a high frequency of fractures [141-146], with a seriously impairement in the mobility and in the quality of life at a young age. Immobility, development of epilepsy and anticonvulsant medications are all factors that can contribute to the development of osteoporosis [95, 141].

\section{Therapy}

Pre-clinical research strongly suggests that RS could be one of the first curable neurological disorders. The application of genome-wide approaches and increasingly sophisticated model systems are painting a clearer picture in the functional role of MeCP2 in neurons, and this new information promises to guide future therapeutic strategies [141, 142]. Bisphosphonates constitute a beneficial adjuvant treatment to diminish the risk of fracture and restore bone density. In addition, anabolic treatment with teriparatide produces a great improvement in the bone microarchitecture in patients with RS [143, 144].

Table 5 describes the neurological disorders with bone involvement.

\section{Malformation Syndrome}

Thricho-rhino-phalangeal syndrome (Langer-Giedion Syndrome)

\section{Description of the systemic disease}

Trichorhinophalangeal syndrome (TRPS) is a rare, autosomal dominant malformation syndrome characterized by hair, craniofacial and skeletal abnormalities, skin laxity, deformation of phalanges and anomalies of pelvis, femurs, and tibias [144].

\section{Genetic defect}

The TRPS1 gene (OMIM: 604386) is located on 8q24.12 and encodes for a zinc-finger (ZF) transcriptional repressor, Trps1. Trps1 binds DNA through a single GATA-type ZF that recognizes a DNA consensus sequence common to all GATA transcription factors. However, the repression activity of Trps1 maps to the C- terminal Ikaros-like double ZF motif [145]. Genotype - phenotype correlation analyses revealed that three distinctive clinical types of TRPS are associated with different kinds of the TRPS1 gene mutations [145]. The mildest form, TRPS type I, is caused mostly by entire gene deletions and nonsense mutations located before the region coding for the DNAbinding domain. Missense mutations in the DNA- binding domain cause the more severe TRPS type III. TRPS type II (Langer-Gideon syndrome) combines features of TRPS type I and multiple exostoses and it is caused by contiguous deletion of the TRPS1 and EXT1 genes [145].

\section{Pathophysiology of the bone phenotype}

Previous studies identified the Trps1 transcription factor as a potentially novel transcriptional repressor both of the Runx 2 promote, the master regulator of osteoblast differentiation and of chondrocyte hypertrophy [146]. Interestingly, during the development of endochondral bones, Trps1 is highly expressed in regions where Runx2 is downregulated [146]. The loss of repression of Runx2-ihh loop in Trps1 knockout mice results in altered endochondral bone formation, which is characterized by dysregulation of chondrocyte differentiation and uncoupling of processes of perichondrial mineralization and chondrocyte maturation [146, 147]. Biphosponate infusional therapy seemed to be effective, both in terms of 
clinical (absence of new fractures) and densitometric parameters, and can be considered as a possible therapeutic option in case of bone fragility in patients with TRPS [147] (Table 6).

Table 6 describes the malformative syndrome.

\section{Conclusions}

The knowledge of the impact of non-skeletal diseases on bone metabolism is of paramount importance for the therapy of bone complications and can guide the clinician in the choice of the most appropriate pharmacological intervention. The changes in bone metabolism require a particular attention considering that, due to better targeted therapies, patients survive into adulthood and in many cases the loss of bone mass may be an important problem to decrease the quality of life. An adequate patient education in term of intake of calcium, vitamin D and physical activity should be recommended. Currently, the best advice is to treat osteopenia and/or osteoporosis according to general guidelines using anti-resorbitives or anabolic drugs. The evolution of drug development for osteoporosis, from clinical observations to the more recent framework of fundamental bone biology driving novel therapeutics, is truly remarkable. Several drugs can be used to improve bone mass and to reduce fracture risk in osteoporosis. These drugs may have an antiresorbitive, an anabolic or a bone building effect on bone. The characterization of bone metabolism for the boneforming or bone-resorbing phenotype in patients with non skeletal diseases in origin, will lead to different therapeutic approaches (e.g., anabolic, antiresorptive or bone building drugs).

\begin{abstract}
Abbreviations
IOF: International Osteoporosis Foundation; SRD-WG: Skeletal Rare Diseases Working Group; LSDs: Lysosomal storage diseases; GD: Gaucher disease ERT: enzyme replacement therapy; CBS: Cystathionine- $\beta$-synthase; HCY: Homocysteine; PLP: Pyridoxal 5'-phosphate; VDR: Vitamin D Receptor; BMD: Bone mineral density; ECM: Extracellular matrix; OA: Osteoarthritis; Phe: Phenylalanine; Cu: Copper; ATPase: Adenosine triphosphatase; WD: Wilson disease; CFTR: Cystic fibrosis transmembrane conductance regulator; CFBD: Cystic fibrosis bone disease; MCs: Mast cells; SM: Systemic mastocytosis; RANK: Receptor Activator of Nuclear Factor k B; RANK-L: RANK-Ligand; TKIs: Tyrosine kinase inhibitors; Hb: Hemoglobin; TM: Thalassemia major; SCD: Sickle cell disease; HSCT: Hematopoietic stem cell transplantation; SCN: Severe congenital neutropenia; ANC: Absolute neutrophil count; ECD: Erdheim-Chester disease; IHC: Immunohistochemical; IFN: Interferon; RS: Rett syndrome; TRPS: Trichorhinophalangeal syndrome; BSAP: Bone specific alkaline phosphatase; NTX: Corss-linked N-telopeptide of type I collagen; OCN: Osteocalcin; DPD: Deoxypyridinoline; PYR: Pyridinoline; CTX: Corss-linked C-telopeptide of type I collagen; OPG: Osteoprotegerin; PTH: Parathyroid Hormone; [1,25(OH) $\left.2 \mathrm{D}_{3}\right]$ : 1,25-Dihydroxy vitamin $\mathrm{D}_{3} ; 25(\mathrm{OH})$ D3: 25 Hydroxyvitamin D3; IL-1a: Interleukin 1 alpha; TNF-a: Tumor necrosis factor alpha; IL-6: Interleukin 6; P1NP: Procollagen type $1 \mathrm{~N}$-terminal propeptide.
\end{abstract}

\section{Acknowledgements}

This paper was supported by F.I.R.M.O. Foundation (to MLB).

\section{Authors' contributions}

All authors were involved equally in the conception, writing, proofreading and approval of the manuscript. All authors read and approved the final manuscript.

\section{Funding}

Not applicable.

\section{Availability of data and materials Not applicable.}

Ethics approval and consent to participate Not applicable.

\section{Consent for publication}

Not applicable.

\section{Competing interests}

The authors declare that they have no competing interests.

\section{Author details}

${ }_{1}^{1}$ Metabolic Bone Diseases Unit, University Hospital of Florence, AOU-Careggi, Florence, Italy. ${ }^{2}$ Division of Bone Diseases, Faculty of Medicine, Geneva University Hospital, Geneva, Switzerland. ${ }^{3}$ Oxford NIHR Musculoskeletal Biomedical Research Unit, University of Oxford, Oxford, UK. ${ }^{4}$ Center for Bone Quality, Leiden University Medical Center, Leiden, The Netherlands. ${ }^{5}$ International Osteoporosis Foundation (IOF), Rue Juste-Olivier 9, 1260 Nyon, Switzerland. ${ }^{6}$ Fondazione Italiana Ricerca sulle Malattie dell'Osso, Florence, Italy. ${ }^{7}$ Department of Biomedical, Experimental and Clinical Sciences, University of Florence, Florence, Italy

Received: 30 July 2020 Accepted: 10 November 2020

Published online: 06 January 2021

\section{References}

1. Sims NA, Martin TJ. Coupling the activities of bone formation and resorption: a multitude of signals within the basic multicellular unit. Bonekey Rep. 2014;3:481.

2. Mirza F, Canalis E. Management of endocrine disease: secondary osteoporosis: pathophysiology and management. Eur J Endocrinol. 2015;173:R131-151.

3. Masi L, Agnusdei D, Bilezikian J, Chappard D, Chapurlat R, Cianferotti L, et al. Taxonomy of rare genetic metabolic bone disorders. Osteoporos Int. 2015;26:2529-58.

4. de Duve C. Lysosomes, new group of cytooplasmic particles. In: Hayashi Teditor Subcellular particles New-York: Ronald Press 1059; 128-159

5. De Duve C. From cytases to lysosomes. Fed Proc 1064; 23:1045-1049

6. de Duve C. Lysosomes revisited. Eur J Biochem. 1983;137:391-7.

7. Duve C. Exploring cells with a centrifuge. Science 1075; 189:186-194

8. Futerman AH, van Meer G. The cell biology of lysosomal storage disorders. Nat Rev Mol Cell Biol. 2004;5:554-65.

9. Gaucher PCE. De l'epithelioma primitif de la rate, hypertrophie idiopathique de la rate sans leucémie [MD Thesis]. 1882; Paris, France.

10. Fabry J. Ein beitrag zur Kenntnis der Purpura haemorrhagica nodularis (purpura papulosa haemorrhagica Hebrae). Arch Dermatol Syph. 1898;43:187-200.

11. Kruer MC, Steiner RD, Griesemer DA. Lysosomal Storage Disease. 2013; Medscape

12. Wang RY, Bodamer OA, Watson MS, Wilcox WR; ACMG Work Group on Diagnostic Confirmation of Lysosomal Storage Diseases. Lysosomal storage diseases: diagnostic confirmation and management of presymptomatic individuals. Genet Med 2011; 13:457-484

13. Dingle JT. The role of lysosomal enzymes in skeletal tissues. J Bone Joint Surg Br. 1973;55:87-95.

14. Page-Thomas DP. Lysosomal enzymes in experimental and rheumatoid arthritis. In Lysosomes in Biology and Pathology Edited by JT Dingle and HB Fell Amsterdam, Holland 1969; 2:87-110 
15. Platt FM, Boland B, van der Spoel AC. The cell biology of disease: Iysosomal storage disorders: the cellular impact of lysosomal dysfunction. J Cell Biol. 2012;199:723-34.

16. Marcucci G, Zimran A, Bembi B, Kanis J, Reginster JY, Rizzoli R, et al. Gaucher disease and bone manifestations. Calcif Tissue Int. 2014;95:477-94.

17. Safary A, Khiavi M, Omidi Y, Rafi MA: Targeted enzyme delivery systems in disorders: an innovative form of therapy for mucopolysaccharidosis. Cell Mol Life Sci. https://doi.org/10.1007/s00018-019-03135-z

18. Andria G, Fowler B, Sbatio G (2000) Disorders of sulfur amino acid metabolism. In: J. Fernandes et al (ed) Inborn metabolic diseases. Springer, Berlin, 18:224-231

19. Miles EW, Kraus JP. Cystathionine $\beta$-synthase: structure, Function, regulation, and location of homocystinuria causing mutations. J Biol Chem. 2004;279:29871-4

20. Reish O, Townsend D, Berry SA, Tsai MY, King RA. Tyrosinase inhibition due to interaction of homocyst(e)ine with copper: the mechanism for reversible hypopigmentation in homocystinuria due to cystathionine beta-synthase deficiency. Am J Hum Genet. 1995;57:127-32.

21. Testai FD, Gorelick PB. Inherited metabolic disorders and stroke part 2: homocystinuria, organic acidurias, and urea cycle disorders. Arch Neurol. 2010;67:148-53.

22. Yap S. Homocystinuria due to cystathionine $\beta$-synthase deficiency. Orphanet encyclopedia, February 2005. http://wwworphanet/data/ patho/GB/uk-CbSpdf

23. Mudd SH, Levy HL, and Kraus JP (2002) in The metabolic and molecular bases of inherited disease (Scriver, C. R., Beaudet, A. L., Valle, D., Sly, W. S., Chiles, D., Kinsler, K. W., and Vogelstein, B., eds) 8th Ed., Vol. 2, pp. 2007-2056, McGraw-Hill, Inc., New York

24. Kraus JP, Janosik M, Kozich V, Mandell R, Shih V, Sperandeo MP, et al. Cystathionine beta-synthase mutations in homocystinuria. Hum Mutat. 1999;13:362-75.

25. Robert K, Maurin N, Vayssettes C, Siauve N, Janel N. Cystathionine beta synthase deficiency affects mouse endochondral ossification. Anat Rec A Discov Mol Cell Evol Biol. 2005;282:1-7.

26. Kriebitzsch C, Verlinden L, Eelen G, van Schoor NM, Swart K, Lips P, et al. 1,25-dihydroxyvitamin D3 influences cellular homocysteine levels in murine preosteoblastic MC3T3-E1 cells by direct regulation of cystathionine beta-synthase. J Bone Miner Res. 2011;26:2991-3000.

27. Saposnik G, Ray JG, Sheridan P, Lonn E. Homocysteine-lowering therapy and stroke risk, severity, and disability: additional findings from the HOPE 2 trial. Stroke. 2009;40:1365-72.

28. Majors AK, Pyeritz RE. A deficiency of cysteine impairs fibrillin-1 deposition: implications for the pathogenesis of cystathionine beta-synthase deficiency. Mol Genet Metab. 2000;70:252-60.

29. Lim JS, Lee DH. Changes in bone mineral density and body composition of children with well-controlled homocystinuria caused by CBS deficiency. Osteoporos Int. 2013;24:2535-8.

30. van Meurs JB, Dhonukshe-Rutten RA, Pluijm SM, van der Klift M, de Jonge R, Lindemans J, et al. Homocysteine levels and the risk of osteoporotic fracture. N Engl J Med. 2004;350:2033-41.

31. Morris AM, Kožich V, Santra S Andria G, Ben-Omran TI, Chakrapani AB, et al. Guidelines for the diagnosis and management of cystathionine beta-synthase deficiency. J Inherit Metab Dis 2017; 40:49-74

32. Mistry JB, Bukhari M, Taylor AM. Alkaptonuria. Rare Dis 2013; 1:e27475

33. Watts RW, Watts RA. Alkaptonuria: a 60-year follow-up. Rheumatology (Oxford). 2007;46:358-9.

34. Fernández-Cañón JM, Granadino B, Beltrán-Valero de Bernabé $D$, Renedo M, Fernández-Ruiz E, Peñalva MA,et al. The molecular basis of alkaptonuria. Nat Genet 1996; 14:19-24.

35. Taylor AM, Boyde A, Wilson PJ, Jarvis JC, Jarvis JC, Davidson JS, Hunt $J A$, et al. The role of calcified cartilage and subchondral bone in the initiation and progression of ochronotic arthropathy in alkaptonuria. Arthritis Rheum. 2011;63:3887-96.

36. Catterall JB, Barr D, Bolognesi M, Robert D, Zura RD, Kraus VB. Post-translational aging of proteins in osteoarthritic cartilage and synovial fluid as measured by isomerized aspartate. Arthritis Res Ther. 2009;11:R55.

37. Phornphutkul C, Introne WJ, Perry MB, Bernardini I, Murphey MD, Fitzpatrick DL, et al. Natural history of alkaptonuria. N Engl J Med. 2002;347:2111-21.
38. Balint G, Szebenyi B. Hereditary disorders mimicking and/or causing premature osteoarthritis. Baillieres Best Pract Res Clin Rheumatol. 2000;14:219-50.

39. Felson DT, Neogi T. Osteoarthritis: is it a disease of cartilage or of bone? Arthritis Rheum. 2004:50:341-4.

40. Karsdal MA, Leeming DJ, Dam EB, Henriksen K, Alexandersen P, Pastoureau $P$, et al. Should subchondral bone turnover be targeted when treating osteoarthritis? Osteoarthritis Cartilage. 2008;16:638-46.

41. Aliberti G, Pulignano I, Schiappoli A, Minisola S, Romagnoli E, Proietta M. Bone metabolism in ochronotic patients. J Intern Med. 2003;254:296-300.

42. Intronea WY,. Perryb PB, Troendlec J, Tsiloud E, Kaysere Ma, Suwannarate $\mathrm{P}$, et al. A 3-year randomized therapeutic trial of nitisinone in Alkaptonuria. Mol Genet Metab 2001; 103(4): 307-314

43. Lee YW, Lee DH, Kim ND, Lee ST, Ahn JY, Choi TY, et al. Mutation analysis of $\mathrm{PAH}$ gene and characterization of a recurrent deletion mutation in Korean patients with phenylketonuria. Exp Mol Med. 2008;5:533-40.

44. Schouten JP, McElgunn CJ, Waaijer R, Zwijnenburg D, Diepvens F, Pals $G$. Relative quantification of 40 nucleic acid sequences by multiplex ligation-dependent probe amplification. Nucleic Acids Res. 2002;30:e57.

45. Demirdas S, Coakley KE, Bisschop PH, Hollak CE, Bosch AM, Singh RH. Bone health in phenylketonuria: a systematic review and meta-analysis. Orphanet J Rare Dis. 2015;10:17.

46. van Wegberg AMG, MacDonald A, Ahring K, Bélanger-Quintana A, Blau $\mathrm{N}$, Bosch AM, et al. The complete European guidelines on phenylketonuria: diagnosis and treatment. Orphanet J Rare Dis. 2017;12:162.

47. Sadeghi N, Oveisi MR, Jannat B, Jannat B, Hajimahmoodi M, Behzad M, et al. The relationship between bone health and plasma zinc, copper lead and cadmium concentration in osteoporotic women. J Environ Health Sci Eng. 2014;12:125.

48. Turnlund JR. Human whole-body copper metabolism. Am J Clin Nutr. 1998;67:960S-964S

49. Cartwright GE. Copper metabolism in human subjects In: McElroy WD, Glass B, eds Symposium on copper metabolism Baltimore: John Hopkins Press 1950; 274-314.

50. Scheinberg IH, Sternlieb I. Copper metabolism. Pharmacol Rev. 1960;12:355-81.

51. Lutsenko S, Barnes NL, Bartee MY, Dmitriev OY. Function and regulation of human copper-transporting ATPases. Physiol Rev. 2007;87:1011-46.

52. Amador E, Domene R, Fuentes C, Carreño JC, Enríquez G. Long-term skeletal findings in Menkes diseases. Pediatr Radiol. 2010;40:1426-9.

53. Stanley PH, Gwinn JL, Sutcliffe J. The osseus abnormalities in Menkes syndrome. Ann Radiol (Paris). 1976;19:167-72.

54. Kanumakala S, Boneh A, Zacharin M. Pamidronate treatment improves bone mineral density in children with Menkes disease. J Inherit Metab Dis. 2002;25:391-8.

55. Ogataa R, Chonga PF, Maeda K. Long surviving classical Menkes disease treated with weekly intravenous copper therapy. J Trace Elem Med Biol. 2019:54:172-4.

56. Esmaeili L, Perez MG, Jafari M, Paquin J, Ispas-Szabo P, Pop V, et al. Copper complexes for biomedical applications: structural insights, antioxidant activity and neuron compatibility. J Inorg Biochem. 2019:192:87-97.

57. Teradaa K, Schilskyb ML, Miuraa N, Sugiyama T. ATP7B (WND) protein. Int J Biochem Cell Biol. 1998:30:1063-7.

58. Merle U, Schaefer M, Ferenci P, Stremmel W. Clinical presentation, diagnosis and long-term outcome of Wilson's disease: a cohort study. Gut. 2007:56:115-20.

59. Weiss KH, Van de Moortele M, Gotthardt DN, Pfeiffenberger J, Seessle J, Ullrich $\mathrm{E}$, et al. Bone demineralisation in a large cohort of Wilson disease patients. J Inherit Metab Dis. 2015;38:949-95.

60. Xie YZ, Zhang XZ, Xu XH, Zhen-xin Z, Yiung-kun F. Radiologic study of 42 cases of Wilson disease. Skeletal Radiol. 1985;13:114-9.

61. Hegedus D, Ferencz V, Lakatos PL Meszaros S, Lakatos P, Horvath C, et al. Decreased bone density, elevated serum osteoprotegerin, and beta cross-laps in Wilson disease. J Bone Miner Res 2002; 17:1961-1967.

62. Kikuyama A, Fukuda K, Mori S, Okada M, Yamaguchi H, Hamanishi C. Hydrogen peroxide induces apoptosis of osteocytes: involvement of calcium ion and caspase activity. Calcif Tissue Int. 2002;71:243-8.

63. Michael L. Schilsky: Wilson Disease: diagnosis, treatment, and follow-up. Clin Liver Dis - (2017) https://doi.org/10.1016/j.cld.2017.06.011 
64. Heinz WK, Aftab A, Frederick A. WTX101 in patients newly diagnosed with Wilson disease: final results of a global, prospective phase 2 trial. Amsterdam: EASL; 2017. Late Breaking Abstract.

65. Brewer GJ, Askari F, Lorincz MT, Carlson M, Schilsky M, Kluin KJ, et al. Treatment of Wilson disease with ammonium tetrathiomolybdate: IV. Comparison of tetrathiomolybdate and trientine ina double-blind study of treatment of the neurologic presentation of Wilson disease. Arch Neurol 2006; 63:521-7.

66. (2011) Orphan Lung Disease. In: European Respiratory Society Monographs; J-F Cordier Ed 1-341.

67. Davies JC, Alton EW, Bush A. Cystic fibrosis. BMJ. 2007;335:1255-9.

68. Riordan JR, Rommens JM, Kerem B, Alon N, Rozmahel R, Grzelczak Z, et al. Identification of the cystic fibrosis gene: cloning and characterization of complementary DNA. Science. 1989;245:1066-73.

69. Bobadilla JL, Macek M Jr, Fine JP, Farrell PM. Cystic fibrosis: a worldwide analysis of CFTR mutations-correlation with incidence data and application to screening. Hum Mutat. 2002;19:575-606.

70. Donaldson SH, Boucher RC. Sodium channels and cystic fibrosis. Chest. 2007;132:1631-6.

71. Mischler EH, Chesney PJ, Chesney RW, Mazess RB. Demineralization in cystic fibrosis detected by direct photon absorptiometry. Am J Dis Child. 1979;133:632-5.

72. Jacquot J, Delion M, Gangloff S, Braux J, Velard F. Bone disease in cystic fibrosis: new pathogenic insights opening novel therapies. Osteoporos Int 2016:27:1401-12.

73. Stalvey MS, Clines KL, Havasi V, McKibbin CR, Dunn LK, Chung WJ, Clines GA. Osteoblast CFTR inactivation reduces differentiation and osteoprotegerin expression in a mouse model of cystic fibrosis-related bone disease. PLoS One 20013; 13, 8:e80098

74. Shapiro BJ, Veeraraghavan S. Lung transplantation for cystic fibrosis: an update and practical considerations for referring candidates. Curr Opin Pulm Med. 1999;5:365-70.

75. Bronckers A, Kalogeraki L, Jorna HJ, Bervoets TJ, Lyaruu DM, ZandiehDoulabi B, et al. The cystic fibrosis transmembrane conductance regulator (CFTR) is expressed in maturation stage ameloblasts, odontoblasts and bone cells. Bone. 2010;46:1188-96.

76. Liang $H$, Yang L, Ma T, Zhao Y. Functional expression of cystic fibrosis transmembrane conductance regulator in mouse chondrocytes. Clin Exp Pharmacol Physiol. 2010;37:506-8.

77. Gimenez A, Le Henaff C, Norez C, Guillaume C, Ravoninjatovo B, Laurent-Maquin $D$, et al. Deficit of osteoprotegerin release by osteoblasts from a patient with cystic fibrosis. Eur Respir J. 2012;39:780-1.

78. Matsuzaki E, Hiratsuka S, Hamachi T, Takahashi-Yanaga F, Hashimoto Y, Higashi K, et al. Sphingosine-1-phosphate promotes the nuclear translocation of beta-catenin and thereby induces osteoprotegerin gene expression in osteoblast-like cell lines. Bone. 2013;55:315-24.

79. Rogan MP, Reznikov LR, Pezzulo AA, Gansemer ND, Samuel M, Prather RS, et al. Pigs and humans with cystic fibrosis have reduced insulinlike growth factor 1 (IGF1) levels at birth. Proc Natl Acad Sci USA. 2010;107:20571-5.

80. Rafeeq MM, Murad HAS. Cystic fibrosis: current therapeutic targets and future approaches. Rafeeq Murad J Transl Med. 2010;15:8.

81. Misbahuddin M, Rafeeg and Murad Has. Cystic fibrosis: current therapeutic targets and future approaches. Refeeq Murad J Transl Med 2015; 15:84

82. Memorial Sloan Kettering Cancer Center

83. Teti A, Teitelbaum SL. Congenital disorders of bone and blood. Bone. 2019:119:71-81.

84. Gulen T, Hagglund H, Dahlen B, Nilsson G. Mastocytosis: the puzzling clinical spectrum and challenging diagnostic aspects of an enigmatic disease. J Intern Med. 2016;279:211-28

85. Johnson MR, Verstovsek S, Jorgensen JL, Manshouri T, Luthra R, Jones DM, et al. Utility of the World Heath Organization classification criteria for the diagnosis of systemic mastocytosis in bone marrow. Mod Pathol. 2009:22:50-7.

86. Nagata H, Worobec AS, Oh CK, B A Chowdhury, STannenbaum, Y Suzuki, et al. Identification of a point mutation in the catalytic domain of the protooncogene c-kit in peripheral blood mononuclear cells of patients who have mastocytosis with an associated hematologi disorder. Proc Natl Acad Sci USA 1995; 92:10560-10564
87. Barete S, Assous N, de Gennes C, Grandpeix C, Feger F, Palmerini F et al. Systemic mastocytosis and bone involvement in a cohort of 75 patients. Ann Rheum Dis. 2010;69:1838-41.

88. Vaes M, Benghiat FS, Hermine O (2017) Targeted Treatment Options in Mastocytosis. Frontiers in Medicine Vol. 4, Article 110

89. Rossini M, Zanotti R, Orsolini G, Tripi G, Viapiana O, Idolazzi L, et al. Prevalence, pathogenesis, and treatment options for mastocytosis-related osteoporosis. Osteoporos Int. 2016;27:2411-21.

90. Herman M, Chaudry S. Thalassemia McMaster Pathophysiology Review 2018

91. Thein SL. Pathophysiology of beta thalassemia--a guide to molecular therapies. Hematology Am Soc Hematol Educ Program 2005; 31-37

92. De Sanctis V, Stea S, Savarino L, Scialpi V, Traina GC, Chiarelli GM, et al. Growth hormone secretion and bone histomorphometric study in thalassaemic patients with acquired skeletal dysplasia secondary to desferrioxamine. J Pediatr Endocrinol Metab. 1998;11(Suppl 3):827-33.

93. Voskaridou E, Terpos E. New insights into the pathophysiology and management of osteoporosis in patients with beta thalassaemia. $\mathrm{Br} J$ Haematol. 2004;127:127-213.

94. Skordis N, Toumba M. Bone disease in thalassaemia major: recent advances in pathogenesis and clinical aspects. Pediatr Endocrinol Rev. 2011;8(Suppl 2):300-6.

95. Marcucci G, Brandi ML. Rare causes of osteoporosis. Clin Cases Miner Bone Metab. 2015;12:151-6.

96. Morabito N, Gaudio A, Lasco A, Atteritano M, Pizzoleo MA, Cincotta M, et al. Osteoprotegerin and RANKL in the pathogenesis of thalassemia induced osteoporosis: new pieces of the puzzle. J Bone Mineral Res. 2004; 19:722-7.

97. Mansouritorghabeh H. Clinical and laboratory approaches to hemophilia A. Iran J Med Sci. 2015;40:194-205.

98. Mansouritorghabeh $\mathrm{H}$, Rezaieyazdi Z. Bone density status in bleeding disorders: where are we and what needs to be done? J Bone Metab. 2017:24:201-6.

99. Oldenburg J. Optimal treatment strategies for hemophilia: achievements and limitations of current prophylactic regimens. Blood. 2015:125:2038-44.

100. Gallacher SJ, Deighan C, Wallace AM, Cowan RA, Fraser WD, Fenner JA, et al. Association of severe haemophilia A with osteoporosis: a densitometric and biochemical study. Q J Med. 1994;87:181-6.

101. Iorio A, Fabbriciani G, Marcucci M, Brozzetti M, Filipponi P. Bone mineral density in haemophilia patients. A meta-analysis. Thromb Haemost. 2010:103:596-603.

102. Booth J, Lu M, Gallo D, Ito D, ValentinO LV. Increased risk of adverse bone health outcomes in people with bleeding disorders. Blood. 2016;128:250.

103. Hathaway WE, Christian MJ, Clarke SL, Hasiba U. Comparison of continuous and intermittent Factor VIII concentrate therapy in hemophilia A. Am J Hematol. 1984;17(1):85-8.

104. Fomi ME, Togarrati PP, Muenc MM. Progress and challenges in the development of a cell-based therapy for hemophilia A. J Thromb Haemost. 1988;12(12):1954-2196.

105. Dolana G, Bensonb G, Duffyc A. Haemophilia B: Where are we now and what does the future hold? Blood Rev 2018; 52-66

106. Khawaji M, Akesson K, Berntorp E. Long-term prophylaxis in severe haemophilia seems to preserve bone mineral density. Haemophilia. 2009;15:261-6.

107. Kawar N, Alrayyes S, Compton AA, Aljewari H, Baghdan D, Yang B, Goreishi R, Mohama S. Sickle cell disease; An overview of the disease and its systemic effects. Diseases of Month https://doi.org/10.1016/j.disam onth.2018.12.008

108. Almeida A, Roberts I. Bone involvement in sickle cell disease. Br J Hae matol. 2005:129:482-90.

109. Osunkwo I. An update on the recent literature on sickle cell bone disease. Wolters Kluwer Health | Lippincott Williams \& Wilkins (2013)

110. Sarrai M, Duroseau H, D'Augustine J, Moktan S, Bellevue R. Bone mass density in adults with sickle cell disease. $\mathrm{Br} J$ Haematol. 2007: 136: 666-672

111. Khemani K, Katoch D, Krishnamurti L. Curative therapies for sickle cell disease Ochsner Journal 2019:19:131-7. 
112. Arora R, Aggarwal S, Deme S. Ghosal hematodiaphyseal dysplasiaa concise review including an illustrative patient. Skeletal Radiol. 2015;44:447-545

113. Geneviève D, Proulle V, Isidor B, Bellais S, Serre V, Djouadi F, Picard C, Vignon-Savoye C, Bader-Meunier B, Blanche S, de Vernejoul M-C, Legeai-Mallet L, Fischer A-M, Le Merrer M, Dreyfus M, Gaussem P, Munnich A, Cormier-Daire V. Thromboxane synthase mutations in an increased bone density disorder (Ghosal syndrome). Nat Genet. 2008;40:284-6.

114. Sharma R, Schwartz JE, Nalepa G. Chronic pancytopenia and increased bone density due to TBXAS1 deficiency. Blood. 2016;128:1503.

115. Sharma R, Potchanant ES, Schwartz JE, Nalepa G. Chronic steroidresponse pancytopenia and increased bone density due to thromboxane synthase deficiency. Pediatr Blood Cancer. 2018:65:e26777.

116. Borzutzky ML, Reyes V, Figueroa C, García C, Cavieres M. Osteoporosis in children with severe congenital neutropenia: bone mineral density and treatment with bisphosphonates. J Pediatr Hematol Oncol. 2006;28:205-9.

117. Rosenberg PS, Alter BP, Bolyard AA, Bonilla MA, Boxer LA, Cham B, et al. The incidence of leukemia and mortality from sepsis in patients with severe congenital neutropenia receiving long-term G-CSF therapy. Blood. 2006;107:4628-35.

118. Elhasid R, Hofbauer LC, Ish-Shalom S, Ben-Arush M, Koc O, Rowe JW. Familial severe congenital neutropenia associated with infantile osteoporosis: a new entity. Am J Hematol. 2003;72:34-7.

119. Writing Group of the Histiocyte Society. Histiocytosis syndromes in children. Lancet 1987; i: 208-209

120. Favara BE, Feller AC, Pauli M, Jaffe ES, Weiss LM, Arico M. Contemporary classification of histiocytic disorders. The WHO Committee On Histiocytic/Reticulum Cell Proliferations. Reclassification Working Group of the Histiocyte Society. Med Pediatr Oncol 1997; 29:157-166

121. Shahlaee AH (2008) Histiocytic disorders In Arceci RJ, Hann IM, Smith OP, editors Pediatric Hematology 3rd ed Hoboken, NJ: Wiley 340-35

122. Lian C, Lu Y. Shen S Langerhans cell histiocytosis in adults: a case report and review of the literature. Oncotarget. 2016;7:18678-83.

123. Keen RW Ischemic and infiltrative disorders. In: Primers on the Metabolic Bone Diseases and Diosrders of Mineral Metabolism Eighth Edition Wiley-Blackwell (Ed. J Rosen) 805-809

124. Makras P, Terpos E, Kanakis G, Papatheodorou A, Anastasilakis AD, Kokkoris $\mathrm{P}$, et al. Reduced bone mineral density in adult patients with Langerhans cell histiocytosis. Pediatr Blood Cancer. 2012;58:819-22.

125. Makras P, Polyzos SA, Anastasilakis AD, Terpos E, Kanakis G, Schini $M$, et al. Serum osteoprotegerin, RANKL, and Dkk-1 levels in adults with Langerhans cell histiocytosis. J Clin Endocrinol Metab. 2012;97:E618-621

126. Monsereenusorn C, Rodriguez-Galindo C. Clinical characteristics and treatment of langerhans cell histiocytosis. Hematol Oncol Clin North Am. 2015;29:853-73.

127. Makras P, Salagianni M, Revelos K, Anastasilakis AD, Schini M, Tsoli $M$, et al. Rationale for the application of RANKL inhibition in the treatment of Langerhans cell histiocytosis. J Clin Endocrinol Metab. 2015;100:E282-286.

128. Makras P, Tsoli M, Anastasilakis AD, Thanou M4, Kaltsas G. Denosumab for the treatment of adult multisystem Langerhans cell histiocytosis. Metabolism 2017; 69:107-111

129. Chester W. Lipoidgranulomatose. Virchows Arch Pathol Anat. 1930;279:561-602.

130. Diamond EL, Dagna L, Hyman DH, Cavalli G, Janku F, Estrada-Veras J, et al. Consensus guidelines for the diagnosis and clinical management of Erdheim-Chester disease. Blood. 2014;124:483-92.
131. Dion E Graef C Miquel A Haroche J, Wechsler B, Amoura Z, et al. Bone involvement in Erdheim-Chester disease: imaging findings including periostitis and partial epiphyseal involvement. Radiology. 2006;238:632-9.

132. Badalian-Very G, Vergilio JA, Degar BA, MacConaill LE, Brandner B, Calicchio ML. Recurrent BRAF mutations in Langerhans cell histiocytosis. Blood 2010; 116:1919-1923

133. Mazor RD, Manevich-Mazor M, Shoenfeld Y. Erdheim-Chester Disease: a comprehensive review of the literature. Orphanet J Rare Dis. 2013:8:137.

134. Civesa M, Simonea V, Rizzoa FM. Erdheim-Chester disease: a systematic review. Crit Rev Oncol Hematol. 2015;95(1):1-11.

135. Lloyd ME, Spector TD, Howard R. Osteoporosis in neurological disorders. J Neurol Neurosurg Psychiatry. 2000;68:543-9.

136. Amir RE, Van den Veyver IB, Wan M, Tran CQ, Francke U, Zoghbi HY. Rett syndrome is caused by mutations in X-linked MECP2, encoding methylCpG-binding protein 2. Nat Genet. 1999;23:185-8.

137. Julu PO, Kerr AM, Apartopoulos F, Al-Rawas S, Engerstrom I, Engerstrom $L$, et al. Characterisation of breathing and associate central autonomic dysfunction in the Rett disorder. Arch Dis Child. 2001;85:29-37.

138. Ellison KA, Fill CP, Terwilliger J, DeGennaro LJ, Martin-Gallardo A, Anvret $M$, et al. Examination of $X$ chromosome markers in Rett syndrome: exclusion mapping with a novel variation on multilocus linkage analysis. Am J Hum Genet. 1992;50:278-87.

139. Jefferson AL, Woodhead HJ, Fyfe S, Briody J, Bebbington A, Strauss BJ, et al. Bone mineral content and density in Rett syndrome and their contributing factors. Pediatr Res. 2011;69:293-8.

140. Nan X, Ng HH, Johnson CA, Laherty CD, Turner BM, Eisenman RN, et al. Transcriptional repression by the methyl-CpG-binding protein MeCP2 involves a histone deacetylase complex. Nature. 1998;393:386-9.

141. Lotan M, Reves-Siesel R, Eliav-Shalev RS, Merrick J. Osteoporosis in Rett syndrome: a case study presenting a novel management intervention for severe osteoporosis. Osteoporos Int. 2013;24:3059-63.

142. Shah RR, Bird AP. MeCP2 mutations: progress towards understanding and treating Rett syndrome. Genome Med. 2017;9:17.

143. Zanchetta MB, Scioscia MF, Zanchetta JR. Bone microarchitecture in Rett syndrome and treatment with teriparatide: a case report. Osteoporos Int. 2016;27:2873-7.

144. Jefferson A, Leonard $H$, Siafarikas A, Woodhead H, Fyfe S, Ward LM, et al. Clinical guidelines for management of bone health in rett syndrome based on expert consensus and available evidence. PLOS ONE. 2016;11:e0146824.

145. Ludecke HJ, Schaper J, Meinecke P, Momeni P, Gross S, von Holtum D, et al. Genotypic and phenotypic spectrum in tricho-rhino-phalangeal syndrome types I and III. Am J Hum Genet. 2001;68:81-91.

146. Napierala D, Garcia-Rojas X, Sam K, Wakui K, Chen C, Mendoza-Londono $\mathrm{R}$, et al. Mutations and promoter SNPs in RUNX2, a transcriptional regulator of bone formation. Mol Genet Metab. 2005:86:257-68.

147. Macchiaiolo M, Mennini M, Digilio MC, Buonuomo PS, Lepri FR, Gnazzo $\mathrm{M}$, et al. Thricho-rhino-phalangeal syndrome and severe osteoporosis: a rare association or a feature? An effective therapeutic approach with biphosphonates. Am J Med Genet A. 2014;164A(3):760-3.

\section{Publisher's Note}

Springer Nature remains neutral with regard to jurisdictional claims in published maps and institutional affiliations. 